\title{
YIHADISMO, DESCONEXIÓN, DESRADICALIZACIÓN, ADOCTRINAMIENTO Y DEFENSA SOCIAL ${ }^{1}$
}

\author{
Tàlia González Collantes \\ Profesora de Derecho Penal y miembro del Instituto Universitario de \\ Investigación en Criminología y Ciencias Penales \\ Universitat de València
}

Title: Jihadism, disengagement; de-radicalization, indoctrination and social defense.

Resumen: En el presente trabajo se analiza el programa español de intervención en radicalización violenta con internos islamistas en centros penitenciarios desde el punto de vista de la resocialización, teniendo en cuenta la diferencia entre desconexión y desradicalización, y poniendo el foco en el respeto por los derechos y libertades fundamentales, pero también, y precisamente por ello, se cuestiona la imbricación de la Instrucción 2/2016, de 25 de octubre, dentro de las políticas securitarias dirigidas a la incapacitación, y particularmente el hecho de que los destinatarios del programa sean incluidos, todos ellos, en los FIES (Ficheros de Internos de Especial Seguimiento).

Palabras clave: Yihadismo; desconexión; desradicalización; adoctrinamiento; defensa social.

Abstract: This text analyses the Spanish program of intervention in violent radicalization with Islamist prisoners from the point of view of resocialization, taking into account the distinction between disengagement and de-radicalization, and focusing on the safeguard of fundamental rights and freedoms, but also, and precisely for this reason, the overlap of Instruction 2/2016, of October 25, within the security policies aimed

${ }^{1}$ Este trabajo se enmarca en el Proyecto I+D+I "Justicia penal preventiva y tutela del orden público" (DER2016-77947-R; Ministerio de Ciencia, Innovación y Universidades, AEI/ FEDER, UE). 
at incapacitation is questioned, and particularly the fact that program participants are placed, all of them, under the FIES (Ficheros de Internos de Especial Seguimiento) System.

Keywords: Jihadism; disengagement; de-radicalization; indoctrination; social defense.

SUMARIO: 1. Introducción. - 2. Prevención, desconexión y desradicalización. - 3. La reincorporación del penado en la sociedad libre con la capacidad y la intención de vivir respetando la ley penal. - 4. La reconducción de las convicciones que sostienen los planteamientos radicales. -5 . El desarrollo de las habilidades cognitivas y el pensamiento prosocial. - 6. La educación en valores democráticos. - 7. El respeto por la libertad religiosa. - 8. La apuesta por la defensa social. - Bibliografía.

\section{Introducción}

El Programa Marco de Intervención en Radicalización Violenta con Internos Islamistas está concebido como parte del tratamiento resocializador ofrecido a sujetos condenados por pertenencia o colaboración con grupos terroristas de corte yihadista, a aquellos otros musulmanes que adoptan una actitud de liderazgo captador y proselitista que facilita el desarrollo de actitudes extremistas y radicales entre la población reclusa, y también a quienes presentan indicios directos o indirectos de fanatismo islamista, en los cuales se presume un mayor o menor nivel de riesgo y vulnerabilidad hacia el proceso de captación. Se pretende la desvinculación y/o la desradicalización de unos, después lo veremos, y evitar el afianzamiento de los planteamientos que pueden desembocar en actitudes terroristas de otros.

En la Instrucción 2/2016, de 25 de octubre, de la Secretaría General de Instituciones Penitenciarias, se dice aspirar a que "cumplida la condena, el penado retorne a la sociedad con la capacidad y la voluntad de vivir respetando la Ley Penal", pero al mismo tiempo se habla de "reconducir las convicciones tan intensas que sostienen los planteamientos de los internos radicales islámicos”, y en el anexo adjunto a la Instrucción, que tiene carácter confidencial, se indica que el objetivo general del programa consiste en "la prevención, el desenganche y la desradicalización de aquellos internos con una asunción arraigada de una ideología extremista”, añadiéndose después, como uno de los objetivos específicos del mismo, el "desactivar el fanatismo religioso, como fuente de radicalismo violento, a través de una interpretación moderada de la religión”, para lo cual se prevé recurrir a imanes, cuya misión es precisamente esta, la promoción de una interpretación moderada de la religión.

Siendo así, lo primero que haré será dejar indicado qué entiende la doctrina especializada por prevención, desenganche y desradicalización, conceptos estos sobre los que se articula la lucha contra el terrorismo en el 
ámbito penitenciario y que deben ser delimitados, sobre todo el segundo y el tercero, porque, como enseguida veremos, y como bien apunta Fernández $\mathrm{Abad}^{2}$, existe en la actualidad una disputa respecto a si en el campo del terrorismo se debe aspirar a lo uno o a lo otro, la cual, por otra parte, viene a reproducir el debate mantenido desde hace mucho tiempo sobre cuál debería ser el significado de la resocialización, entre los defensores de un programa resocializador mínimo y los defensores de otro máximo.

Me propongo, asimismo, en consecuencia, exponer, aunque sin ánimo de exhaustividad, algunas formas de entender la resocialización, para ver si se corresponden con lo manifestado en la indicada Instrucción, y analizar si encontramos aquí una intromisión abusiva e ilegítima por parte de los poderes públicos y el sacrificio de la libertad personal y otros derechos fundamentales de sus destinatarios, y particularmente si con ello se pretende influir en los internos para que cambien su ideología y asuman una determinada orientación religiosa, lo cual podría ser contrario a la libertad religiosa y de pensamiento.

En cualquier caso, y como también comprobaremos, entre los autores que han escrito sobre resocialización hay quienes, como alternativa a los enfoques mínimo y máximo, se pronuncian a favor de darle a aquella un enfoque psicoeducativo, centrado en el desarrollo de las habilidades cognitivas y en la educación para la convivencia pacífica y la integración en la pluralidad. Veremos qué dicen los partidarios del mismo y, también, que con el Programa Marco de Intervención en Radicalización Violenta con Internos Islamistas lo que se ha querido hacer es implementar un programa que responde a dichos postulados.

Ahora bien, no es menos cierto que, como se ha avanzado, el Programa Marco contempla, como elemento reforzador de las técnicas psicosociales a aplicar, el recurso a los imanes moderados, cuya misión es la promoción de una interpretación moderada de la religión, alejada de perspectivas extremistas. Siendo así, surgen una serie de dudas que habrá que responder: ¿realmente se parte de un concepto de la resocialización compatible con la Constitución?, ¿se respetan los límites a los cuales debe estar sujeto un tratamiento resocializador en un Estado social y democrático de Derecho?, ¿seguro que podemos seguir afirmando que no se pretende incidir en la ideología del individuo tratado?

Además, y por último, realizaré una serie de consideraciones críticas respecto a la "clara apuesta por la defensa social" a la que, según consta en la misma Instrucción, obedece el indicado programa. Estas observaciones en realidad no versan sobre el programa en cuestión, sino sobre la imbricación de dicha Instrucción dentro de las políticas securitarias dirigidas no

2 Fernández ABAD, C., "Las prisiones como espacios de oportunidad en la lucha contra el terrrorismo yihadista: ¿Idoneidad de la respuesta española?”, Revista General de Derecho Penal, núm. 34, 2020, p. 29. 
a la resocialización sino a la incapacitación, y particularmente respecto al hecho de que los destinatarios del programa sean incluidos en los Ficheros de Internos de Especial Seguimiento.

\section{Prevención, desconexión y desradicalización}

Igual que sucede con el término resocialización, o con los de reeducación y reinserción social, los de desconexión y desradicalización suelen ser utilizados sin la debida precisión, sin que se sepa muy bien qué se quiere decir con ellos. De hecho, incluso se utilizan a veces indistintamente, como si de términos sinónimos se tratase, y no es así. Es necesario romper con esta imprecisión categorial, entre otras cosas porque como dijo García-Pablos de Molina respecto a la resocialización, "un debate científico-teórico sereno y constructivo no tiene que cargar con tales carencias definitorias, que lo lastran y condicionan" ${ }^{3}$.

Sobre el contenido que se le puede y debe dar a la resocialización nos referiremos más adelante, pero importa dejar claro que el mismo tiene que estar en consonancia con lo establecido en la Constitución, y en el artículo 1.1 de esta se indica que España se constituye en un Estado social y democrático de Derecho, que propugna como valores superiores de su ordenamiento jurídico la libertad, la justicia, la igualdad y el pluralismo político, añadiéndose en el artículo 9.1 que los poderes públicos están sujetos a la Constitución y al resto del ordenamiento jurídico. En base a la Constitución no se puede pretender que los individuos que han delinquido interioricen como propia una moral determinada, ni tampoco las directrices, valores y normas sociales que contribuyen al mantenimiento del orden y la convivencia en una sociedad dada y en un momento histórico concreto, ni siquiera de la ley penal. Cabe decir, asimismo, y en consecuencia, que el tratamiento penitenciario, como instrumento a través del cual se pretende conseguir dicha meta, la resocialización, debe estar sujeto a una serie de límites, como son el respeto por la dignidad, el desarrollo libre de la personalidad y los derechos y libertades fundamentales de las personas, entre los cuales hay que destacar la libertad de pensamiento, de conciencia y de religión y el derecho a la integridad personal, en su dimensión física y moral. Teniendo esto claro, hay que avanzar que, a pesar de que se fije como objetivo general del programa español de intervención en radicalización violenta con internos islamistas en centros penitenciarios la consecución de la prevención, el desenganche y la desradicalización de los sujetos con una asunción arraigada de una ideología extremista, aspirar a esto último, y con ello a un programa resocializador máximo, no resulta legítimo.

3 García-Pablos De Molina, A., "Sobre la función resocializadora o rehabilitadora de la pena”, en Cuadernos de Política Criminal, segunda época, núm. 100, 2010, p. 78. 
Importa saber de qué se habla cuando se utilizan esos tres conceptos sobre los cuales se articula la lucha contra el terrorismo en el ámbito penitenciario, qué debemos entender por prevención, por desenganche o desconexión, y por desradicalización, y una vez delimitado el contenido de los mismos se comprenderá el porqué de la anterior afirmación, que digamos que no es legítimo aspirar a la desradicalización.

Así pues, empezando por la prevención de la radicalización, se entiende por tal el conjunto de medidas dirigidas a un grupo indeterminado de individuos a través de las cuales se pretende evitar su radicalización, medidas que pueden ser de tipo político, social, educativo e incluso religioso ${ }^{4}$.

En segundo lugar, la doctrina especializada define el desenganche o desvinculación como el proceso dirigido a conseguir la renuncia a ejercer violencia por parte de un individuo a través del abandono del grupo u organización de la que forma parte y de la actividad terrorista, sin que tenga que producirse necesariamente una reorientación ideológica, sin buscar, al menos no directa o activamente, que la persona renuncie a un sistema determinado de creencias, lo que implica, por ejemplo, romper con ese grupo u organización pero no condenar el recurso a la violencia ni renunciar a la consecución de los objetivos políticos reivindicados por el mismo ${ }^{5}$.

La desradicalización, sin embargo, sí implica, y exige, un cambio ideológico, el abandono de la ideología extremista del sujeto tratado y la asunción e interiorización, de otras creencias de signo moderado ${ }^{6}$.

4 Revelles Carrasco, M., "Intervención contra el yihadismo en prisión”, InDret, núm. 4, 2020, p. 390; Vidino, L., "Deradikalisierung durch gezielte Interventionen”, Aus Politik und Zeitgeschichte, núm. 29-31, 2013, p. 26.

5 Barrelle, K., "Prointegration: disengagement from and life after extremism", Behavioral Sciences of Terrorism and Political Aggression, vol. 7, núm. 2, 2015, p. 134; CANO PANos, M. A., Régimen Penitenciario de los terroristas en España. La prisión como arma para combatir ETA, Dykinson, Madrid, 2018, p. 6; FERnÁNDEZ ABAD, C., "Las prisiones como 'espacios de oportunidad' en la lucha contra el terrorismo yihadista: ¿Idoneidad de la respuesta española?”, cit., p. 9; HoRGAN, J., “Deradicalization or Disengagment? A process in Need of Clarity and a Counterterrorism Initiative in Need of Evaluation”, Perspectives on Terrorism, vol. 2, núm. 4, 2008, p. 1; RaBAsA, A.- PetTyjohn, S.L. - Ghez, J. - BouceK, C., Deradicalizing Islamist Extremist, National Security Research Division, Santa Mónica, p. XIII (disponible online en: https://www.rand.org/content/dam/ rand/pubs/monographs/2010/RAND_MG1053.pdf; fecha de la última consulta: 1 de abril de 2021); REINARES, F., "Exit from Terrorism: Qualitative Empirical Study on Disengagement and Deradicalization Among Members of ETA", Terrorism and Political Violence, vol. 23, 2011, p. 780; Revelles CARRASCO, M., "Intervención contra el yihadismo en prisión”, cit., p. 390.

6 FERnÁNDEZ ABAD, C., "Las prisiones como 'espacios de oportunidad' en la lucha contra el terrorismo yihadista: ¿Idoneidad de la respuesta española?”, cit., pp. 9 y 28; HoRGAN, J. - AltiER, B., "The Future of Terrorism De-Radicalization Programs", Georgetown Journal of International Affairs, vol. 13, núm. 2, 2012, p. 86, KOEHLER, D., Understanding Deradicalization. Methods, tools and programs for countering violent extremism, Routledge, New York, 2017, pp. 2 y 3; NEuman, P., "Radikalisierung, Deradikasierung und Extremismus", Aus Politik und Zeitgeschicte, núm. 29-32, 2013, p. 7; Revelles Carrasco, M., "Intervención contra el yihadismo en prisión", cit., p. 390. 
Fácilmente se entenderá, pues, nuestro rechazo a aspirar a esta meta, porque supone intervenir sobre la ideología del individuo, porque estaríamos ante una injerencia injustificada en su esfera interna. A esta y a otras críticas hacia los programas orientados a la desradicalización nos referiremos más adelante, cuando nos refiramos a las críticas dirigidas contra los programas resocializadores máximos.

\section{La reincorporación del penado en la sociedad libre con la capacidad y la intención de vivir respetando la ley penal}

Tal y como se ha avanzado, mediante la Instrucción 2/2016, de 25 de octubre, de la Secretaría General de Instituciones Penitenciarias, se aprueba el Programa Marco de Intervención en Radicalización Violenta con Internos Islamistas. En la propia Instrucción se justifica el programa indicando que "La Administración Penitenciaria, además de garantizar la retención y custodia durante el cumplimiento de la pena, tiene la obligación de propiciar el conjunto de actividades directamente encaminadas a conseguir la reeducación y reinserción social de los penados, de forma que, cumplida la condena, el penado retorne a la sociedad con la capacidad y la voluntad de vivir respetando la Ley Penal". Esta es la definición genérica, o blanca, si se prefiere, del tratamiento penitenciario y el contenido a dar a la resocialización que se recoge en el artículo 59 de la Ley Orgánica General Penitenciaria. Se parte, pues, al menos aparentemente, de un concepto legal de resocialización. Con ello parece que la meta a conseguir es el respeto externo por la legalidad penal ${ }^{7}$.

Es verdad que la referencia no sólo a la capacidad sino también a la intención de vivir respetando la ley penal ha sido criticada. Vale de ejemplo de que es así lo dicho por Cobo de Rosal y Vives Antón, según los cuales con ello se estableció "una regulación que se dirige, no sólo al aspecto externo de la conducta, sino al ánimo (a la intención), excediendo así el ámbito propio

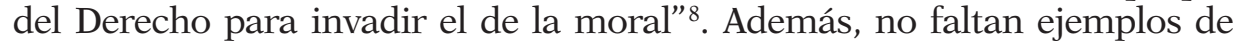
autores que, buscando la mejora ciudadana, la educación en la legalidad, no se han conformado con el respeto externo por ésta, como es el caso de los

7 En cualquier caso, hay que apuntar que si analizamos con detalle los diferentes artículos sobre el tratamiento de la Ley Orgánica General Penitenciaria de 1979 comprobaremos que en realidad se parte de un concepto restringido de aquel, que responde a los predicados de la criminología clínica. Además, y por otra parte, aunque esa definición del tratamiento como conjunto de actividades dirigidas a conseguir la resocialización de las personas condenadas a privación de libertad también está recogida en el Reglamento de 1996, este rompe con la criminología clínica y acoge una idea más amplia de aquel.

8 Cobo Del Rosal, M. y Vives Antón, T.S., Derecho Penal. Parte General, quinta edición, Tirant lo Blanch, Valencia, 1999, p. 48, nota 14. 
alemanes Nass ${ }^{9}$ y Blau ${ }^{10}$. Sin embargo, a pesar de que pudiera parecer que es como apuntan Cobo del Rosal y Vives Antón, el hecho de que tanto en la Constitución como también en la normativa penitenciaria se exija el respeto por la dignidad y el libre desarrollo de la personalidad y derechos y libertades de las personas presas, llevaría a descartar esta interpretación.

No se puede aspirar a que la persona que ha delinquido interiorice los valores contenidos en las normas penales, pero sí a conseguir que quiera vivir al margen del delito, que asuma que el Derecho Penal es de cumplimiento obligatorio. Ello no supone un contrasentido. Como apuntan los autores citados: "la obligatoriedad de sus normas (las penales) no depende del convencimiento empírico del destinatario sobre la adecuación de aquéllas, sino de la voluntad soberana que las asume e impone" ${ }^{11}$. Es más, no solo no hay problema en pedir el respeto por la legalidad penal, sino que, como apunta Muñoz Conde, esta interpretación es consecuente con la estructura funcional del sistema sancionador penal. Si la norma penal contiene una serie de expectativas de conducta legalmente determinada, y su frustración posibilita, bajo ciertas condiciones, la aplicación de una pena, es coherente que se diga que la finalidad de la ejecución de esta pena es el restablecimiento en el delincuente del respeto por esas normas, haciéndole corresponder en el futuro a las expectativas en ellas contenidas, evitando así la comisión de nuevos delitos. Aparte de ello, nada puede objetarse a la imposición coactiva de tal respeto por la legalidad penal, porque las normas jurídicas, a diferencia de las morales, pueden imponerse, y de hecho se imponen, coactivamente ${ }^{12}$.

9 Nass, G., Der Mensch und die Kriminalität, vol. III, Kriminalpädagogik, Behandlung und Resozialisierung des Rechtsverbrechers, Carl Heymanns, Köln, 1968.

10 BlaU, G., “Aufgaben und Grenzen der Kriminalpädagogik”, en Vv. Aa., Erziehung zur Freiheit durch Freiheitsentzung, Internationale Problem des Strafvollzugs an jungen Menschen, Hermann Luchterhand, Berlín, 1969; del mismo autor, "Kustodial und antikustodiale Tendenzen in der amerikanischen Kriminalpolitik”, Goltdammers Archiv, 1976, pp. 33 y 35.

11 Cobo Del Rosal, M. y Vives Antón, T.S., Derecho Penal. Parte General, cit., pp. 37 y 38, nota 22. Paréntesis añadido. Aquí se indica que "la obligación jurídico-penal, como obligación política, y a diferencia de la obligación moral, no se apoya exclusivamente en el consentimiento empírico del ciudadano concreto (...) ya que, si así fuera, ni el orden político como tal, ni la organización jurídica de la comunidad podrían subsistir". Vid., también, PLAMENATZ, J.P., Libertad, consentimiento y obligación política, Fondo de Cultura Económica, México, 1970, p. 31; y MANZANARES SAMANIEGO, J.L., "Concepto, voluntariedad y principios inspiradores del tratamiento”, en CoBo Del Rosal, M., Comentarios a la Legislación Penal. La Ley Orgánica General Penitenciaria, Edersa, Madrid, 1986, tomo VI, vol. II, p. 918. Este último autor indica que no ve ningún problema en exigir la intención de vivir sin delinquir, ya que, según él, "si el tratamiento es voluntario, no veo inconveniente ni contradicción en que alguien con un largo historial delictivo y voluntad habitual criminal desee simultáneamente aprender una profesión y modificar el esquema de intenciones en el que hasta el presente se había movido. Más todavía, un tratamiento que sólo avanzara en lo relativo a la satisfacción de las necesidades propias podría ser contraproducente, elevando incluso la peligrosidad del penado (piensen en la formación puramente cultural o técnica de un estafador impenitente)".

12 Muñoz Conde, F., "La resocialización del delincuente, análisis y crítica de un mito", en Cuadernos de Política Criminal, núm.7, 1979, p. 96. Vid., también, MaPelli CafFarena, 
Importa subrayar, por otra parte, que algunos autores, como García-Pablos de Molina, critican que este es un enfoque puramente formal y minimalista, que "renuncia a la necesidad de cualquier cambio motivacional y actitudinal en el recluso, en su marco axiológico y de valores", que se conforma con el pronóstico razonable de no reincidencia y que ello "no es exigir suficiente, ni tranquiliza", que "implica una renuncia 'ex ante' a cualquier objetivo pedagógico, incluso al de ofrecer programas que amplíen el mapa cognitivo y emocional de las personas condenadas, que enriquezcan su horizonte y perspectivas de participación social y de abordaje de problemas y situaciones que no pueden resolverse sin vencer sus limitaciones preexistentes" ${ }^{13}$. Sin embargo, en realidad son muy pocos los autores que dan un significado tan restrictivo a la resocialización legal, con lo cual podemos afirmar que los defensores de esta forma de entender la resocialización renunciarían a la desradicalización, pero no necesariamente a la desvinculación, la cual en principio hace únicamente referencia a un aspecto meramente comportamental, pero implica cambios cognitivos y emocionales en la persona.

No hay problema, pues, en partir de un concepto legal de la resocialización y reconocer que no se debe renunciar a que los programas de tratamiento incluyan técnicas de aprendizaje cognitivo, entre otras cosas porque se ha demostrado que los que las incluyen resultan más efectivos para prevenir la recaída en el delito. No habría problema en que así sea siempre y cuando el tratamiento sea totalmente voluntario y las técnicas se apliquen con el propósito de desarrollar la personalidad y ampliar las posibilidades de participación social de los individuos tratados, sin pretender cambios cualitativos profundos en la estructura íntima de su personalidad.

\section{La reconducción de las convicciones que sostienen los planteamientos radicales}

En la Instrucción 2/2016 no solo se indica que con el Programa Marco de Intervención en Radicalización Violenta con Internos Islamistas se pretende la reincorporación del penado en la sociedad libre con la capacidad y la intención de vivir respetando la ley penal. También se dice que se aspira a "reconducir las convicciones tan intensas que sostienen los planteamientos de los internos radicales islámicos". Ello hace que se trate de un programa polémico, pues esto sí que podría transgredir

B., Principios fundamentales del sistema penitenciario español, Bosch, Barcelona, 1983, p. 58; y Bergalli, R., ¿Readaptación social por medio de la ejecución penal?, Instituto de Criminología de Universidad Complutense, Madrid, 1976, p. 43.

13 García-Pablos De Molina, A., "Sobre la función resocializadora o rehabilitadora de la pena”, cit., pp. 80 y 81 . 
los límites del Derecho Penal, podría no respetar el ámbito interno de la persona, su libertad ideológica, religiosa y de culto, la dignidad y el libre desarrollo de su personalidad. Precisamente por ello he entendido pertinente referirme, sin ánimo de exhaustividad, a algunas formas de entender la resocialización que no se contentan con fomentar la conformidad formal del comportamiento externo y se caracterizan por querer pasar al aspecto interno de la conducta, planteamientos que han sido criticados por las razones apuntadas. Me referiré, por tanto, a algunas concepciones planteadas por los defensores de los llamados programas resocializadores máximos ${ }^{14}$.

A lo largo de la historia se han escuchado muchas voces partidarias de entender la resocialización en el sentido de corrección interior de los condenados, y empezando por quienes se han propuesto que los individuos que han delinquido interioricen como propia una moral determinada, es decir, moralizarlos, es menester referirse a los correccionalistas, entre quienes es preciso hacer mención a Roeder, el formulador del correccionalismo en el Derecho Penal, como teoría de la pena. Roeder aspiraba a conseguir la enmienda o cambio interno del ánimo o voluntad injusta de la persona que ha delinquido, para que de este modo recuperase la capacidad de hacer un uso correcto de su libertad exterior. La "voluntad mala y egoísta", decía el alemán, "tiene que ser el objetivo verdadero de la reacción jurídico-penal"; esta "voluntad inmoral tiene que ser extirpada de raíz, según su clase y grado, sustituyéndola por la voluntad moral, el querer justo, el deseo justo". Roeder planteaba la necesidad de una "posteducación de los individuos abandonados, completamente incultos o sumidos en la corrupción de costumbres y en la barbarie, mediante un influjo benefactor sobre el fundamento interno u origen de su injusticia, esto es, sobre el error del juicio y del sentimiento, y, por consiguiente, de la voluntad sobre el Derecho". Lo que pretendía era, según él, la "rehabilitación interior para la libertad exterior plena y su retorno mediante tal requisito a la sociedad civil" 15 .

El correccionalismo tuvo buena acogida en España ${ }^{16}$, y aunque se dice que la mayoría de los juristas dieron una interpretación propia a esta teoría, lo cierto es que las diferencias no son significativas. Una figura destacada del correccionalismo español fue Arenal, la cual explicaba que la "corrección corresponde a lo que se ha denominado

14 Respecto a las diferentes concepciones dadas a lo largo de la historia de la resocialización, vid. González Collantes, T., El concepto de resocialización (Desde un punto de vista histórico, sociológico, jurídico y normativo), Tirant lo Blanch, Valencia, 2021.

15 Roeder, C.D., Estudios sobre Derecho Penal y sistemas penitenciarios: fundamento jurídico de la pena correccional, traducción a cargo de Vicente Romero Girón, Imprenta de T. Fortanet, Madrid, 1875, pp. 153, 154, 157 y 160 a 163.

16 Cerezo Mir, J., Curso de Derecho Penal español Parte General, sexta edición, Tecnos, Madrid, 2004, vol. I, p. 102. 
honradez legal; la enmienda a la virtud, a la honradez verdadera, a la moralidad"; decía que "corregirse es mejorar la conducta y enmendarse es mejorar de pensamiento, de deseos, variar las causas de las alegrías y de los dolores; cambiar, en fin, el modo de ser moral". Sin embargo, tras hacer esta distinción aseguraba que se "corrige a quien se equivoca para que se enmiende" ${ }^{17}$. Esta autora decía renunciar a adoctrinar a las personas presas, porque "el preso que se manipula como cosa en la prisión no será persona en libertad", pero a pesar de ello, y de que afirmaba que enmendar "no significa transformar a la persona, sino volver a ser la persona que era antes de delinquir, pero fortalecida y escarmentada" 18 , no se conformaba con fomentar el respeto externo por la legalidad, porque, como Roeder, creía que con ello únicamente se conseguiría una corrección a medias.

Por otra parte, no obstante las diferencias entre el planteamiento de Arenal y Dorado Montero en algunos puntos, y tal y como apuntó Antón Oneca, "el espíritu de aquélla estuvo presente en la obra de éste" ${ }^{19}$. Dorado Montero diferenció entre corrección externa o civil e interna o moral, sin rechazar a ninguna de las dos. Él hablaba de la corrección de los penados como proceso pedagógico, como transformación educativa ${ }^{20}$, y a diferencia de Arenal, el sí reconocía sin pudor una obviedad: que detrás de esa forma de entender la resocialización existe la voluntad de conquistar la mente para conseguir la posesión absoluta de la persona. Según él, lo que se pretende conseguir con la pena no es otra cosa que "poner a tono con nuestros deseos los actos de los otros que viven cerca de nosotros y forman parte de nuestro grupo; hacer que quieran y obren como nosotros apetecemos; ganar su confianza, la cual nos da una tranquilidad que de otra manera nos faltaría, y su ausencia es una molestia muy fuerte para nuestra prosperidad y la de los nuestros”. Y partiendo de esto decía: “¿dónde buscar la base de aquella confianza, mejor que en el espíritu del hombre, en su interior, en su voluntad? Dueños de ésta, el resto viene por añadidura; el hombre entero es nuestro y queda convertido en nuestro instrumento, en nuestro auxiliar, en nuestro amigo y colaborador" ${ }^{21}$.

¿Qué decir al respecto? Pues que el Estado no tiene legitimidad para imponer creencias y convicciones internas. A pesar de que puedan apelarse

17 Arenal, C., Estudios penitenciarios, segunda edición, Imprenta de T. Fortanet, Madrid, 1877, pp. 106 y 107.

18 AREnal, C., El visitador del preso, prólogo de Manuela Carmena, edición realizada por la Asociación de Colaboradores con las Presas, Madrid, 1991, pp. 63 y ss.

19 Antón Oneca, J., La utopía penal de Dorado Montero, Universidad de Salamanca, Salamanca 1951, p. 8.

20 Dorado Montero, P., El Derecho protector de los criminales (Nueva edición muy aumentada y rehecha de los Estudios de Derecho Penal preventivo), Victoriano Suárez, Madrid, 1915, vol. I, pp. 25, 89 y ss., 131 y ss., 163 y ss., 176 y ss., 226 y ss., 323 y ss., 379 y ss., y en general a lo largo de la obra. También en el vol. II, pp. 7 y ss., y 126 y ss.

${ }_{21}$ Ibidem, p. 176. 
objetivos altruistas y tutelares, no puede pasarse por alto que, como apunta García-Pablos de Molina, con la defensa de la resocialización moral se asumen unos "objetivos impropios y autoritarios de adoctrinamiento ideológico, de manipulación del individuo a costa del sacrificio de su libertad personal y otros derechos fundamentales", implica, por tanto, "una intromisión abusiva e ilegítima por parte del Estado" 22 . La misma crítica ha sido formulada por Muñoz Conde, quien subraya que la "resocialización entendida en este ámbito moral conduciría a la más absurda y peligrosa manipulación de la conciencia individual", que la misma "no puede llevarse a cabo sin lesionar gravemente los fundamentos de una sociedad pluralista y democrática", que quien la defiende no tiene en cuenta que "por encima de cualquier otro valor está siempre el respeto a la libertad de profesar cualquier creencia o ideología" 23 . Y junto a estos autores, hay otros que comparten dichas críticas, pudiendo citar, a título de ejemplo, a Mapelli Caffarena ${ }^{24}$, a Bacigalupo $^{25}$, a Vives Antón ${ }^{26}$, a González Rus ${ }^{27}$, a de Toledo y Ubieto ${ }^{28}$, a Lamarca Pérez $^{29}$, a de la Cuesta Arzamendi ${ }^{30}$, a Peña Roldán ${ }^{31}$, a Tamarit Sumalla, a García Albero, a Rodríguez Puerta y a Sapena Grau ${ }^{32}$.

22 García-Pablos De Molina, A., Estudios penales, Bosch, Barcelona, 1984, p. 60. Vid., también, del mismo autor, Introducción al Derecho Penal, quinta edición, Editorial Universitaria Ramón Areces, Madrid, 2012, vol. I, p. 290.

23 MuÑoz Conde, F., "La resocialización del delincuente, análisis y crítica de un mito", cit., p. 94.

24 Mapelli Caffarena, B., Principios fundamentales del sistema penitenciario español, cit., p. 14.

25 Bacigalupo, E., "Significación y perspectivas de la oposición 'Derecho Penal-Política Criminal”, Révue Internationalde de Droit Pénal, 1977, pp. 24 y 25.

26 Vives Antón, T.S., "Introducción, Estado de Derecho y Derecho Penal”, en Coвo Del Rosal, M. (Dir.), Comentarios a la Legislación Penal, Derecho Penal y Constitución, Edersa, Madrid, 1982, vol. I, p. 46.

27 GONZÁLEZ RUS, J.J., “Teoría de la pena y Constitución”, en Estudios Penales y Criminológicos, VII, 1982-1983, pp. 275 y 276.

28 Octavio De Toledo Y Ubieto, E., Sobre el concepto del Derecho Penal, Universidad de Madrid, Facultad de Derecho, Sección Publicaciones, Madrid, 1981, p. 215.

29 LAMARCa PÉrez C., "Régimen penitenciario y derechos fundamentales", en Estudios Penales y Criminológicos, núm. 16, 1992-1993, p. 218. La autora afirma que "en una sociedad pluralista y democrática no existe un punto único de referencia ético o moral, sino que, como señala el Tribunal Constitucional, nuestro texto fundamental 'es un marco de coincidencias suficientemente amplio' donde caben múltiples opciones políticas, pero también innumerables concepciones del bien o de la virtud". El Tribunal Constitucional realiza la afirmación reproducida por esta autora en la Sentencia de 8 de abril de 1981, Fundamento Jurídico 7.

30 De La Cuesta Arzamend, J.L., "La resocialización: objetivo de la intervención penitenciaria”, Papers d'Estudis i Formació, núm.12, diciembre de 1993, pp. 9 a 21.

31 Peña Roldán, L., "Resocialización. Un problema de todos", en Anales de Derecho, Universidad de Murcia, núm., 14, 1996, p. 488.

32 Tamarit Sumalla, J.M. - García Albero, R. - Rodríguez Puerta, M.J. - Sapena Grau, F., Curso de Derecho Penitenciario, segunda edición, Tirant lo Blanch, Valencia, 2005, p. 47. 
Hay que tener en cuenta, asimismo, que no vivimos en una sociedad hermética y monolítica, que una sociedad pluralista y democrática como la nuestra no puede ofrecer al individuo un modelo unitario y definido de pautas de conducta, porque la misma no las tiene, y en este punto quisiera volver a citar a García-Pablos de Molina: "La resocialización exige un modelo de referencia, compacto, definido, hacia el cual tiene que acercarse o identificarse (a los programas máximos) el individuo. Y la sociedad actual no puede ofrecer tal modelo, porque el caos de concepciones, de ideologías, de estilos, rompe cualquier imagen unitaria y congruente de aquélla. Entonces, si falta esta base, difícil es trazar un objetivo también común" 33 . Así lo reconoció el propio Peters, otro de los defensores de la educación moral, y lo dijo a comienzos en la década de 1970, en pleno auge del ideal resocializador. En palabras de este autor acabado de citar: "tal vez la irrupción definitiva del pensamiento resocializador ha llegado en un tiempo en el que se producen cambios éticos y espirituales, por lo cual ya no es posible una resocialización por falta de fundamentos sólidos. Se ha ganado la batalla, pero se ha perdido la guerra" ${ }^{4}$.

Es más, junto a lo anterior también hay que tomar en consideración que, como apuntan Mapelli Caffarena ${ }^{35}$, Luzón Peña ${ }^{36}$ y Álvarez García $^{37}$, se ha demostrado que no siempre son las personas con las que se ensayan los planes de regeneración moral las que logran la meta de no reincidencia.

Por otra parte, también ha habido voces partidarias de entender que a través de la resocialización lo que se pretende conseguir es que el condenado asuma como propias las directrices, valores y normas sociales que contribuyen al mantenimiento del orden y la convivencia en una sociedad dada y en un momento histórico concreto. Entre quienes así lo han defendido encontramos a Petrus Rotges, según el cual lo que tiene que conseguirse es la "readaptación social de aquellos ciudadanos que, por causas distintas, han permanecido al margen del medio y normas sociales de los grupos", y entre las funciones por él asignadas a la reeducación y reinserción social encontramos la consistente en que el sujeto inadaptado pueda "asumir los esquemas normativos y los valores del

33 García-Pablos De Molina, A., Estudios penales, cit., p. 45. Vid., también, relacionado con la falta de una imagen unitaria de la sociedad y de los modelos y finalidades buscados, MuÑoz CondE, F., "Resocialización y tratamiento del delincuente en los establecimientos penitenciarios españoles”, en La Reforma Penal, Ed. Instituto Alemán, Madrid, 1982, pp. 108 y 109.

34 Peters, K., "Die ethischen Voraussetzungen des Resozialisierungs und Erziehungsvollzuges”, Festschrift für E. Heinitz, núm. 70, 1972, p. 501.

35 Mapelli Caffarena, B., Principios fundamentales del sistema penitenciario español, cit., p. 60.

36 LuZón PeÑA, D., Medición de la pena y sustitutivos penales, Instituto de Criminología, Universidad Complutense, Madrid, 1979, p. 54.

37 Álvarez García, F.J., Consideraciones sobre los fines de la pena en el ordenamiento constitucional español, Comares, Granada, 2001, pp. 62 y 63, nota 144. 
grupo", así como "adquirir la cultura o culturas predominantes en la sociedad” y, también, "adquirir los hábitos conductuales normalizados" 38.

Sin embargo, a esta otra forma de entender la resocialización también debemos renunciar, y los motivos para hacerlo serían exactamente los acabados de exponer. Y no solo eso, pues, como señala Mapelli Caffarena, el sistema penal no puede perder "las garantías jurídicas para multiplicar la eficacia en su lucha contra la antisociabilidad", porque "se corre el riesgo de perder de vista los valores individuales de la persona $\mathrm{y}$, sobre todo, de convertir a aquél en un instrumento de manipulación política" ${ }^{39}$. Y hay que tener en cuenta otra crítica formulada: que la pena de prisión ni es un medio efectivo ni el más idóneo para recuperar o compensar en personas adultas un defecto de socialización ${ }^{40}$. Es más, incluso se ha afirmado que la dinámica esterilizadora de la ejecución penitenciaria es un obstáculo insalvable para el desarrollo de cualquier modalidad terapéutica. Se advierte que la prisión es una institución total que funciona de manera autónoma, que cuenta con sus propias normas, que impone un modelo de conducta y un estilo de vida, que atribuye roles, que cuenta con sistemas y códigos de comunicación propios, etc ${ }^{41}$. La persona que ingresa en prisión, lejos de adaptarse al conjunto de valores, normas y directrices a los cuales se le pretende adaptar, lo hace, o suele hacerlo, a los valores, normas y directrices que aseguran no ya el orden y la convivencia social sino la supervivencia en prisión. Al proceso de incorporación y adaptación a la vida en prisión Clemmer lo denominó "prisionización" 42 y Goffman "enculturación" 43.

Muchas de estas críticas se han dirigido también, lógicamente, contra los programas orientados a la desradicalización, sobre todo frecuentes en Oriente Medio y el Sureste Asiático. Fernández Abad se ha encargado de recogerlas y sintetizarlas, pudiendo alegarse en contra de los mismos, en primer lugar, que puesto que la religión es utilizada para justificar el terrorismo y dando por supuesto que, en el caso del yihadismo, la persona

38 Petrus Rotger, A., "Hacia una pedagogía comunitaria de la pedagogía penitenciaria”, en Pedagogía social: revista interuniversitaria, núm. 7, 1989, p. 72.

39 Mapelli Caffarena, B., Principios fundamentales del sistema penitenciario español, cit., p. 27.

40 Roxin, K., "Sentido y límites de la pena estatal”, en Problemas básicos del Derecho Penal, traducción y notas de Diego-Manuel Luzón Peña, Editorial Reus, Madrid, 1976, p. 32; García-Pablos De Molina, A., Estudios penales, cit., p. 36; De La Cuesta Arzamendi, J.L., "La resocialización: objetivo de la intervención penitenciaria”, cit., pp. 12 y 13; MÜLLER-DiETZ, H., "Strafvollzugsrecht und Strafvollzugsreform", en MschrKrim, 1972, p. 28.

41 Mapelli Caffarena, B., Principios fundamentales del sistema penitenciario español, cit., p. 68; De La Cuesta ARZAmendi, J.L., "La resocialización: objetivo de la intervención penitenciaria”, cit., p. 13; BERGALLI, R., ¿Readaptación social por medio de la ejecución penal?, cit.

42 Clemmer, D., The Prison Community, Holt Rinehart and Winston, New York, 1958.

43 Goffman, E., Asylums: Essays on the Social Situation of Mental Patients and Other Inmates, Doubleday, New York, 1961. 
ha interiorizado una versión errónea y sesgada del islam, se entiende que su resocialización pasa por conseguir que asuma otra versión distinta de esta religión, que en realidad sería la sancionada por el Estado, lo cual no tiene que significar, y no significa, abrazar una versión moderada del mismo. Pensemos en el caso de Arabia Saudí, donde se recurre a estos programas. La interpretación aquí mantenida del islam no es en absoluto un ejemplo de moderación, o al menos no desde una óptica occidental, que implica el respeto por los derechos humanos y las libertades fundamentales de totas las personas, y parte de una idea de la persona como ser dotado de razón y llamado a regir libremente su propio destino, como ser racional y, en consecuencia, éticamente autónomo, dueño de sí mismo. Precisamente por esto, se entenderá que desde los países occidentales se critiquen los programas orientados hacia la desradicalización, porque la consecución de este objetivo pasa por intervenir sobre la ideología del sujeto tratado, poniendo de manifiesto una falta de respeto por los derechos a la libertad religiosa y de pensamiento. No queda claro, además, si la desradicalización solo se refiere a los aspectos de la ideología que justifican y legitiman el uso de la violencia o si tendría que abarcar, también, otros elementos considerados potencialmente nocivos. Y se obvia, por último, que ni el hecho de estar radicalizado conduce necesariamente al terrorismo ni el haber sido sometido o haber participado en un programa de desradicalización garantiza el abandono de la actividad terrorista, aparte de que resulta muy complicado determinar si una persona realmente ha modificado su sistema de creencias, o incluso si es posible conseguir dicha modificación a través de los programas que vienen aplicándose en la actualidad ${ }^{44}$.

Teniendo en cuenta todo cuanto se ha dicho hasta ahora, hay que apuntar, en relación con el programa español de intervención en radicalización con internos islamistas, que, aunque se hable de desradicalización, en base únicamente a la referencia a la reconducción de las convicciones internas de los sujetos tratados no podemos afirmar que se pretenda conseguir un cambio en la ideología y que, por tanto, uno de los objetivos pretendidos sea realmente aquél. Sucede que cuando se enumeran los objetivos fundamentales del programa en cuestión se habla de "la modificación de elementos actitudinales de convicción que pueden determinar la comisión de actos terroristas y/o de colaboración y la justificación de los mismos", pero este propósito aparece junto a otros: "la mejora de la capacidad empática de los internos, el fomento de su autonomía personal y mejora de su autoestima, la formación básica en valores y principios de la convivencia democrática”. Siendo así, parece que

44 Bartlett, J. y Miller, C., “The Edge of Violence: Towards Telling the Difference Between Violent and Non-Violent Radicalization”, Terrorims and Political Violence, núm. 24, 2012, pp. 797-814; FERnÁNDEZ ABAD, C., "Las prisiones como espacios de oportunidad en la lucha contra el terrrorismo yihadista: ¿Idoneidad de la respuesta española?”, cit., pp. 12 y ss. 
lo que realmente se ha querido ha sido implementar un programa basado en modelos psicológicos con un componente cognitivo. Se le ha querido dar al mismo un enfoque psicoeducativo, centrado en el desarrollo de las habilidades cognitivas y en la educación para la convivencia pacífica y la integración en la pluralidad, lo cual se corresponde, además, con una forma alternativa de entender la resocialización, tal y como veremos en el apartado siguiente.

Ahora bien, no es menos cierto que, tal y como se ha avanzado, en el Programa Marco de Intervención en Radicalización Violenta con Internos Islamistas se contempla, como elemento reforzador de las técnicas psicosociales a aplicar, el recurso a los imanes moderados, cuya misión es la promoción de una interpretación moderada de la religión, alejada de perspectivas extremistas. Siendo así, surgen una serie de dudas que deberán ser resueltas: ¿realmente se parte de un concepto de la resocialización compatible con la Constitución?, ¿se respetan los límites a los cuales debe estar sujeto un tratamiento resocializador en un Estado social y democrático de Derecho?, ¿seguro que podemos seguir afirmando que no se pretende incidir en la ideología del individuo tratado? Más adelante nos ocuparemos de esta cuestión.

\section{EI desarrollo de las habilidades cognitivas y el pensamiento prosocial}

A pesar de que, tal y como hemos indicado anteriormente, no resulta incompatible partir de un concepto legal de la resocialización y aceptar, o incluso defender, que se apliquen programas de tratamiento dirigidos a desarrollar las habilidades cognitivas y el pensamiento prosocial, entre los autores que han escrito sobre resocialización hay quienes, como alternativa a aquel enfoque mínimo, y también al máximo al que nos acabamos de referir, se pronuncian a favor de dar un enfoque psicoeducativo a aquella. A continuación veremos qué dicen los partidarios del mismo y, también, que con el Programa Marco de Intervención en Radicalización Violenta con Internos Islamistas lo que se ha querido hacer es implementar un programa que responde a dichos postulados, un programa de intervención que persigue la modificación de factores precursores de la actividad delictiva y la potenciación de elementos alternativos a la misma, y que se configura como "una estrategia de crecimiento personal e integración social”.

En primer lugar se dirá que Ross y Fabiano en la década de 1980 realizaron una exhaustiva revisión de estudios científicos sobre los programas de tratamiento aplicados en las prisiones y comprobaron que los que resultaban más efectivos para prevenir la recaída en el delito eran aquellos que incluían técnicas dirigidas a producir un desarrollo en la cognición de las personas encarceladas, a desarrollar las habilidades 
de razonamiento, a mejorar la sensibilidad ante la consecuencia de su conducta, a enseñar a pensar antes de actuar, a incrementar habilidades para la solución de problemas interpersonales, a ampliar la visión del mundo, a desarrollar interpretaciones alternativas, etc.

A partir de este hallazgo, esos dos autores y Garrido Genovés examinaron la literatura científica y comprobaron que "hay una evidencia empírica impresionante que indica que muchos delincuentes tienen ciertos retrasos en el desarrollo de varias habilidades cognitivas que son esenciales para la adaptación social" 45 . Concluyeron, pues, que "parece obvio que un número importante de delincuentes tienen dificultades en algunos aspectos de su comportamiento", añadiendo, además, que "parece que el área de la cognición social es la más afectada, particularmente la solución de problemas interpersonales y la percepción social" ${ }^{46}$. Y hay estudios posteriores que parece que confirman que la mayoría de las personas presas presentan determinadas características y variables de la personalidad, a saber: impulsividad, rigidez cognitiva, locus de control externo elevado, baja tolerancia a la frustración, ausencia de pensamiento abstracto y crítico, baja autoestima, egocentrismo, baja capacidad de autoestima, falta de habilidades sociales y cognitivas específicas para afrontar situaciones interpersonales conflictivas y problemáticas de manera constructiva, distorsiones graves de tipo perceptivo y valorativo en la esfera cognitiva, emocional y afectiva para entender correctamente las reglas y convenciones sociales, etc ${ }^{47}$.

Importa aclarar que los citados autores se han preocupado por dejar muy claro que la suya no es una teoría de la delincuencia, que de cuanto ellos afirman no se deriva que las personas delincan debido a un funcionamiento cognitivo deficiente. Los mismos aseguran que "no estamos sugiriendo que los déficits de pensamiento sean una causa de la delincuencia" 48 y advierten que "no todos los delincuentes manifiestan tales déficits; hay quienes cometen delitos perfectamente racionales, y están muy planeados, obteniendo resultados provechosos”, además de que los "delincuentes no son los únicos individuos que presentan déficits en el pensamiento" y que "muchas personas bien inteligentes, ajustadas, y socialmente productivas, manifiestan alguno de los mismos déficits que han sido encontrados entre los delincuentes". También explican que a pesar de existir estudios que revelan una vinculación

45 Ross, R.R., FABIANO, E. y GARrido GEnovés, V., "El pensamiento prosocial. El modelo cognitivo para la prevención y tratamiento de la delincuencia”, en Delincuencia, núm. 1, monográfico, 1990, p. 18.

46 Ibidem, p. 34.

47 A título de ejemplo, vid. Garrido Genovés, V., Técnicas de tratamiento para delincuentes, Cera S.A., Madrid, 1993, pp. 73 a 88; García-Pablos De MolinA, A., "Sobre la función resocializadora o rehabilitadora de la pena”, cit., p. 78.

48 Ross, R.R., Fabiano, E. y Garrido Genovés, V., "El pensamiento prosocial. El modelo cognitivo para la prevención y tratamiento de la delincuencia”, cit., p. 18. 
entre cognición y delincuencia, los mismos presentan muchos errores en la calidad de la investigación efectuada que limitan el conocimiento que tenemos en relación tanto con la naturaleza como con la extensión de la relación, y que no acostumbran a tener en cuenta que ello puede deberse o estar acentuado por su encierro en prisión, esto es, no contemplan el efecto erosionador que la institucionalización puede tener sobre el funcionamiento cognitivo de los sujetos estudiados, por lo cual las diferencias detectadas entre delincuentes y no delincuentes pueden estar contaminadas por este hecho, aparte de que las investigaciones realizadas sólo tienen en cuenta a los delincuentes detectados por el sistema de justicia penal y no a aquellos otros que no engordan las cifras de la delincuencia oficial ${ }^{49}$. Sin embargo, advertido lo anterior, Ross, Fabiano y Garrido Genovés han subrayado la importancia que tiene el desarrollar las habilidades cognitivas de estas personas, porque son fundamentales para su integración social y porque, además, si se mejora el funcionamiento cognitivo se está contribuyendo a la prevención de la recaída en el delito ${ }^{50}$.

El pensamiento impulsivo, ilógico y egocéntrico puede modificarse gracias a diversas técnicas que desarrollan el autocontrol, el pensamiento consecuente, modos alternativos de respuesta ante problemas interpersonales y la capacidad para ponerse en el lugar de otra persona, teniendo en cuenta el impacto de su conducta en los demás. Y siendo así, y con la intención de enseñar esas destrezas, Ross, Fabiano y Ross desarrollaron un modelo comprehensivo de programa de entrenamiento cognitivo ${ }^{51}$, el cual fue adaptado y aplicado en diversos centros penitenciarios, también españoles. En la Prisión Modelo de Valencia, por citar un ejemplo próximo, gracias, entre otros, a Garrido Genovés, se puso en práctica el programa denominado "El Pensamiento Prosocial", compuesto por una serie de técnicas cuyo denominador común es la importancia que se le da al papel de la cognición en la conducta, entendiendo que el adecuado entrenamiento de funciones cognitivas directamente relacionadas con el ajuste social supone un elemento fundamental en el tratamiento del delincuente ${ }^{52}$. Se apuesta por hacer pedagogía y ofrecer programas que amplíen el mapa cognitivo y emocional de las personas condenadas, para

49 Ibidem, pp. 18, 21 y ss.

50 Ibidem, p. 18. En palabras de los autores referidos: "Nuestra investigación indica que la mejora en el funcionamiento cognitivo del delincuente puede ser un factor esencial en su rehabilitación. Por otra parte, el entrenamiento cognitivo puede servir como medio efectivo para prevenir la delincuencia”.

51 Ross, R., Fabiano, E. Y Ross, R. D., Reasoning and rehabilitatian: cL laidback for teaching cognitive skills, University of Ottawa, Ottawa, 1989.

52 Ross, R., Fabiano, E., Garrido, V. y Gómez, A., El Pensamiento Prosocial: la práctica. Un modelo cognitivo para la prevención y el tratamiento de la delincuencia, MEPSA, Madrid, 1994; GarRido Genovés, V. y PiñAnA, A.M., "El modelo cognitivo aplicado a delincuentes institucionalizados: el pensamiento prosocial", Revista Complutense de Educación, vol. 7, núm. 2, 1996. 
que, en palabras de García-Pablos de Molina, otro de los defensores de los mismos, "enriquezcan su horizonte y perspectivas de participación social y de abordaje de problemas y situaciones que no pueden resolverse sin vencer sus limitaciones preexistentes" ${ }^{53}$. Entre otros, también Redondo Illescas se ha posicionado a favor de dar un enfoque psicoeducativo a la resocialización.

Los defensores de este enfoque desde el principio han sido conscientes de las muchas críticas que el mismo podía suscitar, de forma que se han encargado de matizar unas cuantas cosas en relación con su forma de entender la resocialización ${ }^{54}$. En cualquier caso, aquí interesa saber qué dicen respecto al reproche consistente en que la misma no sólo no garantiza que a través del proceso resocializador el mundo de las convicciones individuales quedará inalterable sino que requiere de un cambio de la realidad subjetiva de la persona que va más allá del acomodo a las normas, lo cual significa una intromisión en la esfera individual e íntima de la persona y plantea peligros de adoctrinamiento y de anulación de voluntades, que no se respete la dignidad de la persona humana. Al respecto quisiera citar en primer lugar a García-Pablos de Molina, quien ha subrayado que el tratamiento basado en el educación social "no reclama cambios cualitativos profundos en la estructura íntima de la personalidad del penado, en sus actividades, motivaciones y valores, lo cual implicaría un 'lavado de cerebro' o intromisión ilegítima del Estado" ${ }^{55}$. Y

53 García-Pablos De Molina, A., "Sobre la función resocializadora o rehabilitadora de la pena”, cit., p. 81 .

54 Por una parte, conscientes de que se les podría criticar que se olvidan de que la resocialización es una modalidad de la prevención especial y que, por tanto, tiene que aspirar a que la persona no vuelva a delinquir, y ellos ni siquiera hablan de aspirar al respeto externo por la legalidad penal, los defensores de este enfoque advierten, como se ha visto, que las habilidades cognitivas que se pretenden desarrollar son fundamentales para su integración social y que si se mejora el funcionamiento cognitivo se contribuye a la prevención de la recaída en el delito. Se ha demostrado empíricamente que los programas de tratamiento aplicados en las prisiones que resultan más efectivos para prevenir la recaída en el delito son los que incluyen técnicas dirigidas a producir un desarrollo en la cognición de las personas presas. También se les podría criticar porque no toman en consideración las consecuencias negativas que tiene la prisión en la persona que la sufre, pero tal y como también se ha visto, los defensores del enfoque psicoeducativo advierten que la prisión reduce el horizonte vital y las expectativas de participación social de la persona que la sufre y que el funcionamiento cognitivo deficiente puede estar causado por el hecho de estar encarcelado. Sí tienen en cuenta, pues, lo devastadora que puede llegar a ser la cárcel. Tampoco se les puede criticar por apostar por unas técnicas concretas de tratamiento y renunciar al resto, puesto que los partidarios de dar este enfoque a la resocialización no desisten de incluir en el tratamiento penitenciario técnicas diferentes a las cognitivas. Como explica Garrido Genovés, emplear “el término cognitivo no supone que 'sólo’ pretendamos emplear unas determinadas técnicas, sino, al contrario, una gran variedad de ellas”, matizando más adelante que se refiere a técnicas que tienen una orientación educativa. GARRIDO GENovés, V., "El modelo cognitivo en la prevención y tratamiento de la delincuencia. Aplicaciones en delincuentes españoles”, en Delincuencia, vol. 1, núm. 2, 1989, p. 236.

55 García-Pablos De Molina, A., "Sobre la función resocializadora o rehabilitadora de la pena”, cit., p. 81 . 
Garrido Genovés y Redondo Illescas, por su parte, puntualizan que detrás de aquella crítica "se esconde la ignorancia tremenda de lo que es, en realidad, un programa de tratamiento o de intervención en un sentido no médico, sino educativo, basado en los modelos de aprendizaje social y la ecología humana". "No se trata de lavarles el cerebro sino de enriquecer su vida"; "no es adoctrinamiento sino modificación de conductas y habilidades"; se pretende "que el sujeto adquiera la posibilidad de elegir entre la acción delictiva y la prosocial" ${ }^{56}$. Ross, Fabiano y Garrido Genovés insisten en que "rechazamos abiertamente el 'moralizar' o 'el aconsejar sobre los valores correctos' a los delincuentes”, y subrayan que no se pretende un "adoctrinamiento o anulación de voluntades" sino que de lo que se trata es de "confrontar su sistema de creencias, suscitando cuestiones que los estimulan para reconsiderar sus puntos de vista y sugiriendo perspectivas alternativas" 57 .

Es por lo anterior que, reproduciendo palabras textuales de Petrus, estos tres autores indican que "el paradigma desde el cual elaboramos nuestra propuesta formativa se enmarca en la perspectiva de una pedagogía social emancipadora crítica" ${ }^{58}$. Y recurriendo a una cita textual de otro autor, de Duguid, añaden que "ser un ciudadano implica más, o al menos tendría que ser así, que el mero cumplimiento de las reglas, ser leal y obediente. Requiere de personas responsables, individuos que hagan decisiones informadas y maduras" ${ }^{59}$. En otras palabras, la resocialización no debe entenderse de manera negativa, únicamente como ausencia de delitos, sino de manera positiva. Se busca capacitar al individuo para que puede alcanzar una auténtica autonomía que le permita integrarse plenamente y ejercer su libertad y derechos sin recurrir al delito. Se puede querer, y se quiere, que la persona no delinca en el futuro, pero no únicamente eso.

Los programas bien estructurados basados en modelos psicológicos con un componente cognitivo no únicamente se están aplicando con éxito en las prisiones, sino que, además, el que se implementen programas específicos de esta clase dirigidos a personas radicalizadas o susceptibles de serlo es una de las recomendaciones realizadas por la Red de Prevención de la Radicalización (RAN: Radicalisation Awareness Network), y a dicha propuesta (y a otras dos, que serían la necesaria consideración al desistimiento criminal, o qué factores de protección harían que algunos internos no se radicalizaran, y la toma en consideración de los niveles individuales de intervención, evitando propuestas generales y universalistas

56 Redondo Illescas, S., GarRIDo Genovés. V., "El tratamiento y la intervención en las prisiones. El ideal de la rehabilitación y la intervención en las prisiones”, en Delincuencia, vol. 3, núm. 3, 1991, p. 294.

57 Ross, R.R., FABIANo, E. y Garrido Genovés, V., "El pensamiento prosocial. El modelo cognitivo para la prevención y tratamiento de la delincuencia”, cit., pp. 6, 10 y 56 .

58 Ibidem, pp. 5 y 6.

59 Ibidem, p. 57. 
y de pretendido amplio espectro que no tengan en cuenta las particularidades personales), se hace referencia expresa en la Instrucción 2/2016, de 25 de octubre, de la Secretaría General de Instituciones Penitenciarias, por la que se aprueba el Programa Marco de Intervención en Radicalización Violenta con Internos Islamistas, donde se señalan como objetivos fundamentales la mejora de la capacidad empática de los internos, el fomento de su autonomía personal y mejora de su autoestima, la formación básica en valores y principios de la convivencia democrática y la modificación de elementos actitudinales de convicción que pueden determinar la comisión de actos terroristas y/o de colaboración y la justificación de los mismos. Se apuesta, pues, por una intervención cognitivo-conductual, para ser más exactos, por un programa psicoeducativo de orientación cognitivo-conductual, por un programa preocupado por desarrollar las habilidades cognitivas de sus destinatarios y por educar para la convivencia pacífica y para la integración en la pluralidad, para conseguir una apropiación libre y crítica de valores cívicos y éticos de convivencia, lo que implica priorizar el respeto a la dignidad humana, la cual se erige en el valor supremo y en el principio jurídico que constituye la columna vertebral básica de todo el ordenamiento constitucional y es fuente de todos los derechos fundamentales en éste reconocidos.

Hay que tener en cuenta, por otra parte, respecto a la dificultad de que este programa específico de tratamiento (como cualquier otro) tenga éxito si se aplica en el medio penitenciario, que la doctrina especializada señala que la desvinculación o desconexión se produce a lo largo de un proceso complejo dividido en diferentes fases, que implica cambios cognitivos y emocionales, y que suele iniciarse a raíz de un evento traumático o de acumulación de una serie de acontecimientos desagradables, y que el hecho de ser encarcelado puede precipitarlo, de ahí que se diga que las prisiones pueden ser un espacio de oportunidad para conseguir esa meta. Encontrándose la persona en dicha tesitura, empezaría una segunda etapa, en la que se sopesan los costes y los beneficios que le supone la desconexión, y si decide desvincularse se entraría en una nueva fase, decidiendo el sujeto cómo se produce la misma, y ya en las siguientes tiene lugar el abandono del grupo u organización, la redefinición de su nueva identidad al margen de esa estructura criminal ${ }^{60}$.

60 Fernández ABAD, C., "Las prisiones como 'espacios de oportunidad' en la lucha contra el terrorismo yihadista: ¿Idoneidad de la respuesta española?”, cit., pp. 20 y 21; KoEHLER, D., Understanding Deradicalization. Methods, tools and programs for countering violent extremism, cit., p. 23; Neuman, P., Prison and Terrorism. Radicalisation and Deradicalisation in 15 countries, The International Centre for the Study of Radicalisation and Political Violence, Maryland, 2010, p. 26 (disponible online en: https://www.clingendael. org/sites/default/files/pdfs/Prisons-and-terrorism-15-countries.pdf; fecha de la última consulta: 1 de abril de 2021); Rabasa, A., Pettyjohn, S.L., Ghez, J. y BouceK, C., Deradicalizing Islamist Extremist, cit., pp. 11 y ss. 
Ahora bien, también hay expertos en la materia que advierten que si el momento del encarcelamiento y la crisis existencial que el mismo puede provocar en el sujeto no son aprovechados, puede producirse el efecto contrario, reforzando esa persona su compromiso en el grupo ${ }^{61}$, y a la hora de tomar una decisión u otra hay una serie de factores que pueden influir en ella, unos relacionados con la experiencia del individuo dentro de la organización, que serán los llamados factores $p u s h^{62}$, y otros, los llamados factores pull ${ }^{63}$, que serían los que proporcionan al individuo una alternativa más gratificante, los que le atraen hacia una vida al margen del grupo u organización, entre los cuales puede citarse la aparición de oportunidades educativas, formativas o laborales, la interacción positiva con personas ajenas a la organización, los beneficios derivados de ciertos instrumentos legales o la existencia de nuevas lealtades, como puede ser la familia.

Pues bien, respecto a la importancia de los factores pull, quisiera, primero, poner en relación cuanto se ha dicho con el concepto de tratamiento resocializador que se desprende del Reglamento Penitenciario, un concepto más amplio del mismo que el recogido en la Ley Orgánica General Penitenciaria ${ }^{64}$. Allí el tratamiento se concibe como el conjunto de actividades, tanto las estrictamente terapéuticas como las formativas,

61 Fernández ABAD, C., "Las prisiones como 'espacios de oportunidad' en la lucha contra el terrorismo yihadista: ¿Idoneidad de la respuesta española?”, cit., p. 21; RABASA, A., Pettyjohn, S.L., Ghez, J. y BouceK, C., Deradicalizing Islamist Extremist, cit., p. XIV.

62 Respecto a los factores push, vid. Altier, M. B., Thoroughgood, C.N. y Horgan, J.G., "Turning away from terrorism: Lessons from psychology, sociology and criminology”, Journal of Peace Research, vol. 51, núm. 5, 2014, p. 649. Sin embargo, estos mismos autores advierten en la página siguiente que esos factores pueden ser determinantes en algunos casos, pero no en todos, ni explican por sí mismos como se desarrolla el proceso de desvinculación o desconexión. Pueden consultarse, además, diversos estudios empíricos en los que se evidencia que dichos factores influyen en el proceso indicado: SPECKHARD, A. Y YAYA, A.S., "Eyewitness Accounts from Recent Defectors from Islamic State: Why They Joined, What They Saw, Why They Quit", Perspectives on Terrorism, vol. 9, núm. 6, 2015, pp. 95-117; y Neumann, P.R., Victims, Perpetrators, Assets: The Narrative of Islamic State Defectors, The International Centre for the Study of Radicalisation and Political Violence, 2015, pp. 1-20 (disponible online en: https://icsr.info/wp-content/uploads/2015/10/ ICSR-Report-Victims-Perpetrators-Assets-The-Narratives-of-Islamic-State-Defectors.pdf; fecha de la última consulta: 30 de marzo de 2021). Vid, también, FERNáNDEz ABAD, C., "Las prisiones como 'espacios de oportunidad' en la lucha contra el terrorismo yihadista: ¿Idoneidad de la respuesta española?”, cit., pp. 16-18.

63 Respecto a los factores pull, vid. Altier, M. B., Thoroughgood, C.N. y Horgan, J.G., "Turning away from terrorism: Lessons from psychology, sociology and criminology", cit., p. 649; y FERNÁNDEZ ABAD, C., "Las prisiones como 'espacios de oportunidad' en la lucha contra el terrorismo yihadista: ¿Idoneidad de la respuesta española?”, cit., pp. 16 y ss.

64 González Collantes, T., "La convivencia de dos conceptos del tratamiento resocializador en el ordenamiento penitenciario español”, Revista General de Derecho Penal, núm. 22, 2014, pp. 9 y ss. En este trabajo se encontrará una relación de los artículos específicos a partir de los cuales se concluye que es ésta la definición contenida en el Reglamento Penitenciario y un comentario exhaustivo respecto a cada uno de los elementos que la integran. 
educativas, laborales, socioculturales, recreativas y deportivas, que se ofrecen a las personas privadas de libertad, a aquéllas que se encuentran cumpliendo condena y, algunas, también a aquéllas otras que se encuentran en situación de preventivas, que se ejecutan con su consentimiento y participación activa por los equipos técnicos, aunque con la colaboración del resto de profesionales de la prisión, así como de los ciudadanos, instituciones y asociaciones públicas y privadas que quieran (y sean autorizadas para hacerlo), respetando los principios de individualización, programación, complejidad, continuidad y dinamismo, y con el propósito de abordar las problemáticas específicas de las condenadas que puedan haber influido en su comportamiento delictivo anterior, de mejorar sus capacidades psicosociales, de desarrollar las aptitudes, enriquecer los conocimientos y mejorar las capacidades técnicas o profesionales y compensar las carencias de todas ellas, y con la vista puesta siempre en su resocialización, además de incluir, igualmente, los contactos con el exterior y de tomar en consideración la importancia de contar con los recursos de la comunidad como instrumentos fundamentales de la tarea resocializadora ${ }^{65}$.

Y aclarado esto, quisiera, además de indicar que el programa específico de intervención contra el yihadismo persigue la modificación de factores precursores de la actividad delictiva y la potenciación de elementos alternativos a la misma, recordar que el mismo está concebido como una parte del tratamiento resocializador, no como el todo.

\section{La educación en valores democráticos}

La educación no es únicamente trasmisión de conocimientos sino también de valores y de pautas de comportamiento necesarias para un adecuado desenvolvimiento de la persona en el medio social en el que vive e interactúa. Debemos reconocerlo. No es fácil imaginar alguna terapia social emancipadora libre de toda carga valorativa, neutra. Es verdad. Y Ross, Fabiano y Garrido asumen, además, que en nuestra sociedad no hay un sistema de valores universalmente aceptado. Pero al mismo tiempo apuntan que "creemos que existe un valor que todos tendríamos que aceptar: la preocupación por los sentimientos de los otros”. Este es, según ellos, "el valor que sí queremos enseñar a los delincuentes, y supone el punto de síntesis de todo el programa cognitivo". En definitiva, concluyen que "el objetivo básico es el desarrollo de la toma de perspectiva social". También hablan de conseguir que "los delincuentes cambien su forma de pensar, que se orienten más hacia el bienestar del resto de los ciudadanos" y no ven ningún problema en esto. "Nadie tiene que rasgarse las vestiduras”, dicen. Y preguntan: “¿Es que no busca esto

65 Ibidem, pp. 29 y ss. 
mismo todo el sistema educativo formal?" ${ }^{66}$. La respuesta a esa pregunta es sí, sin duda, aunque los juristas, cuando hablamos de educar para la convivencia, pues también nosotros lo hacemos cuando tratamos de dar una definición al término resocialización, preferimos referirnos al respeto por los derechos y libertades fundamentales de los demás.

Aspirar a que así suceda no implica una intromisión abusiva e ilegítima por parte del Estado. No significa pretender que la pena asuma unos objetivos impropios y autoritarios de adoctrinamiento ideológico, de manipulación del individuo a expensas del sacrificio de su libertad personal y otros derechos fundamentales. Debe tenerse en cuenta la definición de la educación contenida en el artículo 27.2 de la Constitución Española. Aquí se dice que la misma "tendrá por objeto el pleno desarrollo de la personalidad humana en el respeto a los principios democráticos de convivencia y a los derechos y libertades fundamentales". Siendo así, no debería haber problema en aspirar a que quien ha delinquido, y que haciéndolo se ha apartado de ese respeto debido, vuelva a acatarlos.

En una sociedad pluralista y democrática como la nuestra ${ }^{67}$, que tiene la dignidad, los derechos inviolables que le son inherentes y el libre desarrollo de la personalidad como fundamento del orden político y la paz social ${ }^{68}$, y en la cual se garantiza la libertad ideológica, religiosa y de culto de las personas ${ }^{69}$, no se puede pretender que los individuos que han delinquido interioricen como propia una moral determinada, ni tampoco las directrices, valores y normas sociales que contribuyen al mantenimiento del orden y la convivencia en una sociedad dada y en un momento histórico concreto, ni siquiera la interiorización como propia de la ley, ni de la ley penal ni tampoco de la Constitución. Esto debe quedar claro. Téngase en cuenta, además, que el Tribunal Constitucional en más de una ocasión ha indicado que "la primacía de la Constitución no debe confundirse con una exigencia de adhesión positiva a la norma fundamental, porque en nuestro ordenamiento constitucional no tiene cabida un modelo de 'democracia militante', esto es, 'un modelo en el que se imponga, no ya el respeto, sino la adhesión positiva al ordenamiento y, en primer lugar, a la Constitución" ${ }^{70}$. Pero ese respeto sí que es de debida exigencia y de obligatorio cumplimiento.

En este sentido, hay unas cuantas definiciones de la resocialización planteadas por juristas que me gustaría reproducir. Quisiera empezar por Bueno Arús. Según él hay que apostar por el "desarrollo integral de

66 Ibidem.

67 Artículo 1.1 de la Constitución.

68 Artículo 10.1 de la Constitución.

69 Artículo 16.1 de la Constitución.

70 Pueden consultarse las Sentencias del Tribunal Constitucional 48/2003 (FJ 7), 5/2004, de 16 de enero (FJ 17), 235/2007, de 7 de noviembre (FJ 4), 12/2008, de 29 de enero (FJ 6), 31/2009, de 29 de enero (FJ 13), 42/2014, de 25 de marzo (FJ 4). 
la personalidad, que tiene que tener como consecuencia el respeto a los principios democráticos de convivencia (que son la libertad, la igualdad, la justicia y el pluralismo político, según el artículo $1^{\circ}$ de la Constitución) y a los derechos y libertades fundamentales (de los otros, naturalmente, de acuerdo con el artículo 27.2 de aquélla, y que, como tal, es fundamento del orden político y de la paz social (art. 10.1)" 71 .

González Rus, por su parte, afirmó que por resocialización hay que entender "el proceso tendente a proporcionar al condenado la capacidad y voluntad de operar elecciones de conducta responsables y respetuosas con la ley, en las condiciones propias de una sociedad libre y pluralista”. El autor añadía, además, que "si el delito es el que muestra la conveniencia y oportunidad del proceso reeducativo [...] y éste [...] tiene que limitarse a los casos de atentados a bienes jurídicos constitucionales, la realización de un comportamiento criminal lo que viene a poner de manifiesto es el desconocimiento de los valores constitucionales, por lo cual tendrán que ser estos los que se contengan en 'la oferta' que se hace al sujeto". En síntesis, según González Rus la resocialización es la "tendencia a dar o recordar al reo una sensibilidad por los valores constitucionales ofendidos; esto es, por los significados preeminentes al medio donde se le quiere volver a reinsertar y en el cual las opciones de conducta y las posibilidades de participación están directamente condicionadas al respeto de los valores y principios constitucionales" 72 .

Y también Mena Álvarez apunta que "cabría resumir su concepto, a riesgo, por supuesto, de simplismo, como la reintegración del delincuente en una convivencia social ajena a la práctica del delito. Esta convivencia está basada en los principios democráticos, y en el respeto a los derechos y libertades fundamentales, que son, precisamente, los principios básicos del concepto constitucional de educación" 73 .

Siendo así, no habría nada de objetar a que el Programa Marco en Radicalización Violenta con Internos Islamistas tenga como objetivos fundamentales, aparte de la mejora de la capacidad empática de los internos, el fomento de su autonomía personal y la mejora de su autoestima, la formación básica en valores y principios de la convivencia democrática y la modificación de elementos actitudinales de convicción que pueden determinar la comisión de actos terroristas y/o de colaboración y la justificación de los mismos. Se trata de un programa que solo se aplica a los internos que de manera voluntaria quieran acceder a él y se configura como "una estrategia de crecimiento personal e integración social",

71 Bueno Arus, F., “A propósito de la resocialización del delincuente”, Cuadernos de Política Criminal, núm. 25, 1985, p. 69.

72 GonzÁlez Rus, J.J., “Teoría de la pena y Constitución”, cit., pp. 277 a 279. Consúltense, también, las pp. 275 y 276.

73 Mena Álvarez, J.M., "Reinserción, ¿para qué?”, Revista Jueces para la Democracia, núm. 32, julio 1998, p. 13. 
ofreciendo alternativas y estrategias para ampliar sus perspectivas ante la vida y que afiancen su autoestima y su desarrollo personal e intelectual.

Por otra parte, me parece digno de mención, por positivo, el que a través de la Instrucción 18/2005, de 21 de diciembre, de Normas Generales sobre Internos Extranjeros, se aprobara el Plan Marco de Intervención Educativa, el cual recogía las distintas recomendaciones del Consejo de Europa en esta materia y pretendía servir como enfoque integral de intervención, incluyendo, entre sus líneas de actuación educación en valores democráticos y actividades interculturales abiertas, para que los internos respeten la diversidad cultural, religiones, y diferentes normas y costumbres, para desarrollar valores como la tolerancia y el respeto. Dicha Instrucción ha sido revisada por otra, la Instrucción 3/2019, de 14 de febrero, la cual también incluye una serie de indicaciones sobre tratamiento e intervención educativa con internos extranjeros y, entre los programas educativos especiales, pensados para contribuir a su desarrollo personal e integración de una sociedad democrática, tolerante y pacífica, se menciona el Programa Marco de Intervención con Internos Extranjeros, que recoge las distintas recomendaciones del Consejo de Europa en esta materia y contempla tres áreas de intervención: la educativa, la multicultural y la educación en valores. Es importante que se programen y se lleven a cabo actividades en las que participan presos extranjeros y nacionales, procedentes de diferentes países, con distintas culturas y religiones. Ello no únicamente puede contribuir al rechazo a la violencia terrorista de pretexto religioso-yihadista, sino también al repudio de cualquier forma de racismo, xenofobia o islamofobia, los cuales, aparte de que también impiden per se cualquier proyecto de convivencia pacífica y democrática, son uno de los principales aliados del terrorismo.

\section{EI respeto por la libertad religiosa}

Por las razones apuntadas, el problema no está en los objetivos fundamentales a conseguir enumerados en la Instrucción 2/2016, de 25 de octubre, de la Secretaría General de Instituciones Penitenciarias, esto es, en que no solo se diga que se aspira a que "cumplida la condena, el penado retorne a la sociedad con la capacidad y la voluntad de vivir respetando la Ley Penal", sino que también se hable de "reconducir las convicciones tan intensas que sostienen los planteamientos de los internos radicales islámicos". Sin embargo, hay una cuestión más polémica a la que me quiero referir en este apartado.

Tal y como se ha avanzado, en el anexo adjunto a esa Instrucción, aparte de que entre los objetivos generales del programa está tanto la prevención y el desenganche como la desradicalización de los internos con una asunción arraigada de una ideología extremista, se incluye, como uno de los objetivos específicos del mismo, el "desactivar el 
fanatismo religioso, como fuente de radicalismo violento, a través de una interpretación moderada de la religión”, y, precisamente por ello, en el Programa Marco de Intervención en Radicalización Violenta con Internos Islamistas se contempla, como elemento reforzador de las técnicas psicosociales a aplicar, el recurso a los imanes moderados, cuya misión es la promoción de una interpretación moderada de la religión, alejada de perspectivas extremistas.

Pues bien, además de que puede resultar complicado garantizar que el discurso ofrecido por el imán vaya a estar desprovisto de mensajes englobables en el extremismo violento, debemos plantearnos si con ello se pretende influir en los internos para que asuman una determinada orientación religiosa, si vemos aquí una intromisión ilegítima por parte de los poderes públicos en la libertad religiosa de aquellos ${ }^{74}$. No está de más apuntar que en el artículo 16.1 de la Constitución Española se garantiza la libertad ideológica, religiosa y de culto y que en el artículo 54 de la Ley Orgánica General Penitenciaria se impone a la Administración Penitenciaria la obligación de garantizar la libertad religiosa a los internos y de facilitar los medios necesarios para ello.

En primer lugar, entiendo pertinente que nos preguntemos si el fundamentalismo religioso defensor del uso de la violencia terrorista está amparado por la libertad religiosa, y al respecto importa indicar que, tal y como ha advertido el Tribunal Constitucional, la libertad religiosa e ideológica, en cuanto que derecho subjetivo, se compone de dos fueros: el interno y el externo. El primero garantiza la existencia de un claustro íntimo de creencias y, por tanto, un espacio de autodeterminación intelectual ante el fenómeno religioso, vinculado a la propia personalidad y dignidad individual; mientras que el segundo se refiere al agere licere, que faculta a los ciudadanos para actuar con arreglo a sus propias convicciones y mantenerlas frente a terceros, con plena inmunidad de coacción del Estado o de cualquier grupo social ${ }^{75}$.

Si atendemos a la dimensión interna de la libertad religiosa, hay que reconocer que ésta protege el credo personal en el espacio intelectual, sin que pueda admitirse ninguna restricción; tendría, pues, carácter absoluto, aunque resulte abiertamente contraria a los valores constitucionales. En consecuencia, atendiendo únicamente al fuero interno, a la pregunta si el fundamentalismo religioso defensor del uso de la violencia terrorista está amparado por la libertad religiosa contestaremos afirmativamente.

\footnotetext{
74 Sobre este particular: CArou-García, S., "Yihadismo y Derecho Penitenciario. La prevención del extremismo violento en prisión desde una perspectiva tratamental”, Anuario de Derecho Penal y Ciencias Penales, vol. LXXII, 2019, pp. 556 y ss.

75 SSTC 24/1982, de 13 de mayo (FJ 1), 19/1985, de 13 de febrero (FJ 2), 120/1990, de 27 de junio (FJ 10), 137/1990, de 19 de julio (FJ 8), 166/1996, de 28 de octubre (FJ 2) 177/1996, de 11 de noviembre (FJ 9), 46/2001, de 15 de febrero (FJ 4), 154/2002, de 18 de julio (FJ 6), y 101/2004, de 2 de junio de 2004 (FJ 3).
} 
Sin embargo, si analizamos estas creencias o convicciones radicalizadas en la otra fase de actuación de la libertad religiosa, en ese agere licere, entonces hay que tener en cuenta que sí existen limitaciones, la cuales aparecen fijadas tanto en la Constitución como en la Ley Orgánica 7/1980, de 5 de julio, de libertad religiosa. Efectivamente, el artículo 16.1 de la Constitución establece cuál es el límite del agere licere ideológico o de conciencia, y lo es "el mantenimiento del orden público protegido por la ley”, desarrollándose más esta idea en el artículo 3.1 de la Ley Orgánica de libertad religiosa, donde se indica que "El ejercicio de los derechos dimanantes de la libertad religiosa y de culto tiene como único límite la protección del derecho de los demás al ejercicio de sus libertades públicas y derechos fundamentales, así como la salvaguardia de la seguridad, de la salud y de la moralidad pública, elementos constitutivos del orden público protegido por la Ley en el ámbito de una sociedad democrática”. El derecho a conducirse de acuerdo con los dictados de la propia conciencia, o, si se prefiere, de las propias convicciones o creencias, no faculta para dejar el cumplimiento de los deberes impuestos por una norma jurídica al albur de un juicio privado que se pretende basado en las propias convicciones, y no cabe imaginar mayor inducción al más completo desorden público que dejar al real o pretendido criterio ideológico de sus destinatarios el respeto por los derechos fundamentales consagrados en la Constitución. Si fuera de ese modo, se disolvería la sujeción al Derecho impuesta por el art. 9.1 CE, a tenor del cual "Los ciudadanos y los poderes públicos están sujetos a la Constitución y al resto del ordenamiento jurídico".

Sentado lo anterior, la misión de la Administración Penitenciaria no puede consistir en modificar la ideología de una persona por considerarla extremista o fanática. Es decir, no se puede aspirar a la desradicalización, tal y como la hemos conceptualizado. Además, bajo mi punto de vista, la actuación de la Administración Penitenciaria tampoco debe ir dirigida a promover una determinada interpretación del islam, una visión moderada de éste, alejada de perspectivas extremistas. Es a través de la educación como se debería conseguir el respeto por las libertades y derechos fundamentales, y no a través de la religión, pues de lo contrario siempre quedará la duda de si los poderes públicos pretenden con ello imponer una determinada orientación religiosa, por mucho que se diga que lo que se pretende no es que los religiosos que prestan asistencia espiritual a los reclusos inculquen una visión concreta del islam, sino simplemente que ofrezcan un discurso alternativo a las ideologías religiosas violentas.

Consiguiendo, a través de la educación, que se comprenda la importancia que tiene el valor supremo de la dignidad de las personas y, por tanto, el respeto por los derechos fundamentales de los demás, se podrá conseguir la renuncia a ejercer violencia por parte de un individuo, que se desvincule del grupo u organización, y quizás también se pueda lograr el rechazo absoluto de cualquier justificación de recurso al terrorismo, a 
la violencia o cualquier otra forma de violación de los mismos, $\mathrm{y}$, siendo así, el rechazo a esas visiones extremas de la religión, sea la que fuere. Sin embargo, hay que insistir en que el hecho de estar radicalizado no conduce necesariamente al terrorismo y al uso de la violencia. El tener unas creencias que aquí y ahora pueden considerarse radicales o fanáticas no significa necesariamente que las mismas se defiendan recurriendo a la violencia. Y también hay que insistir en que en el seno de una sociedad plural y democrática no resulta legítimo intervenir sobre la ideología de las personas, puesto que esto supondría una injerencia injustificada en su espera interna, y en concreto una vulneración de su libertad religiosa y de pensamiento ${ }^{76}$.

Ahora bien, lo que sí se puede, y se debe, hacer, y con esto estoy de acuerdo con Carou-García, es impedir que se propaguen "interpretaciones religiosas que, más allá de defender una concreta interpretación radical de la realidad en clave moral, llevan aparejada una llamada al odio, a la discriminación y/o a la violencia contra los no musulmanes", pues en estos casos "se están poniendo en grave riesgo bienes jurídicos elementales de otros reclusos (como la vida o la integridad física), respecto de los cuales la Administración Penitenciaria tiene impuesto un deber legal de protección, conforme al artículo 3 de la LOGP, y más explícitamente, el artículo 4 del RP”, estando en juego, además, el “orden y la seguridad de la prisión", pero también "por las lesivas consecuencias que pueden desprenderse hacia la parte de la sociedad que vive fuera de los muros de la prisión" 77 .

\section{La apuesta por la defensa social}

No he querido entrar a valorar en este trabajo la enfatización del elemento defensor de la sociedad presente de modo explícito en la Instrucción 2/2016, de 25 de octubre, donde se indica que "este Programa Marco de intervención y tratamiento para internos islamistas radicalizados obedece a una clara apuesta por la defensa social, objetivo que también asume la Institución Penitenciaria”. Pero, a pesar de ello, y quiero dejarlo apuntado, comparto las críticas formuladas por autores como Carou-García ${ }^{78}$,

76 De hecho, no estoy de acuerdo con Revellés Carrasco cuando indica que el hecho de que los internos tratados hayan abandonado el uso de la violencia pero no la ideología que la sustenta evidencia la falta de eficacia del Programa Marco. Vid. REvELLEs CARRASCO, M., "Intervención contra el yihadismo en prisión", cit., p. 407. A pesar de hablarse de desradicalización, únicamente se puede aspirar al desenganche o desconexión, y esto parece que sí se está consiguiendo, con lo cual el programa funciona. El marco de intervención no puede aspirar a intervenir sobre la ideología de la persona.

77 Carou-García, S., "Yihadismo y Derecho Penitenciario. La prevención del extremismo violento en prisión desde una perspectiva tratamental”, cit., p. 561.

78 Ibidem, pp. 550 y 551. 
Fernández Abad ${ }^{79}$, Revelles Carrasco ${ }^{80}$ y Acale Sánchez ${ }^{81}$. Quisiera aprovechar estas líneas finales, además, para realizar una reflexión al respecto.

Está claro que a través del tratamiento penitenciario se pretende contribuir a la resocialización de quien se encuentra cumpliendo condena en prisión, esto es, se aspira a fomentar su responsabilidad personal, a que se corresponsabilice del bienestar de la sociedad comprometiéndose a no volver a delinquir ${ }^{82}$, y con ello se contribuye, obviamente, a la defensa social. Siendo así, el que se ponga énfasis en el elemento defensor podría resultar anecdótico, pero no lo es porque los destinatarios del indicado programa previamente han estado incluidos en los Ficheros de Especial Seguimiento, y lo están no sólo los condenados por pertenencia o colaboración con grupos terroristas, sino también los enmarcados en una actitud de liderazgo captador y proselitista que facilita el desarrollo de actitudes extremistas y radicales entre la población reclusa, y, asimismo, los internos que presentan indicios directos o indirectos de fanatismo islamista, en quienes se presume un mayor o menor nivel de riesgo y vulnerabilidad hacia el proceso de captación.

Ya he escrito en otra ocasión sobre los FIES como medida penitenciaria de prevención de atentados, de adiestramiento y reclutamiento con fines terroristas, con lo cual no he querido volver a abordar este tema en este otro trabajo ${ }^{83}$. No obstante, sí quisiera apuntar, en primer lugar, que se parte de una profunda desconfianza hacia estos colectivos,

79 Fernández ABAD, C., "La doble problemática del Terrorismo Yihadista en prisión. Una aproximación crítica a la respuesta del sistema penitenciario español”, InDret, núm. 4, 2020, pp. 330, 331 y 332; y del mismo autor, "Las prisiones como "espacios de oportunidad' en la lucha contra el terrorismo yihadista: ¿Idoneidad de la respuesta española?”, cit., pp. 32 y ss.

80 Revelles Carrasco, M., “Intervención contra el yihadismo en prisión”, cit., 375 y ss.

81 ACALE SÁNChez, M., "Terrorismo y tratamiento punitivista: más allá de la prisión”, en PÉREz CEPEDA, I. (Dir.), El terrorismo en la actualidad: un nuevo enfoque político criminal, Tirant lo Blanch, Valencia, 2018, pp. 449 y 450.

82 Aunque la resocialización no debe aspirar únicamente a ello. También implica al Estado y a la sociedad en su conjunto. A estos se les pide que se responsabilicen del bienestar de dicho sujeto para que pueda reintegrarse en una convivencia social ajena a la práctica del delito y participar en todos los aspectos de la vida en sociedad necesarios para posibilitarle llevar a cabo una vida acorde con la dignidad humana. Con aquello se lograría la reeducación del reo y con esto otro su reinserción social, términos ambos que integran el macroconcepto de resocialización y que, por estar unidos a través de la conjunción "y", se trata de fines yuxtapuestos. En el artículo 25.2 de la Constitución se habla de reeducación y de reinserción social. Se aspira tanto a lo uno como a lo otro, de manera que la pena no cumplirá su objeto constitucional si no se reivindican ambas cosas, si no se trabaja para conseguir ambos designios. Al respecto: GonzÁlez CollanTES, T., El concepto de resocialización (Desde un punto de vista histórico, sociológico, jurídico y normativo), cit, pp. 117 y ss.

83 GonzÁlez Collantes, T., "Prisión y terrorismo yihadista: los FIES como medida penitenciaria de prevención de atentados, de adiestramiento y reclutamiento con fines terroristas", en Alonso Rimo, A., Cuerda Arnau, M.L. y Fernández Hernández, A. (Dirs.), Terrorismo, sistema penal y derechos fundamentales, Tirant lo Blanch, Valencia, 2018. 
hacia los destinatarios del programa específico de tratamiento del que hemos hablado, y ello puede ser negativo para que el mismo tenga éxito. Es importante que los internos musulmanes no se sientan rechazados o discriminados por sus compañeros de reclusión, de ahí que hayamos apuntado lo positivo que resulta que se promuevan actividades interculturales abiertas, dirigidas a todos los internos, tanto nacionales como extranjeros, y dirigidas a que se respete la diversidad cultural, las distintas religiones, y diferentes normas y costumbres, para desarrollar valores como la tolerancia y el respeto. Pero también resulta fundamental que los internos musulmanes no se crean estigmatizados por los trabajadores del centro penitenciario en el que cumplen condena y/o por la propia institución. Ello contribuye a la desconfianza hacia los actores estatales y puede obstaculizar su proceso de resocialización.

Decir cabe, en segundo lugar, que los Ficheros de Internos de Especial Seguimiento formalmente se han limitado a ser una base de datos de carácter administrativo, gestionada por la Dirección General de Instituciones Penitenciarias y en la que se recoge información necesaria para hacer un seguimiento y control de determinados reclusos, pero la obtención de todos esos datos requiere, inevitablemente, la existencia de una serie de mecanismos y prácticas de vigilancia y control, entre otras, las consistentes en el sometimiento a una observación continua durante el día y durante la noche, fuera y dentro de la celda, especialmente cuando se realizan salidas al exterior del departamento para celebrar comunicaciones, asistir a consultas a enfermería o cualquier otra situación que conlleve el abandono del departamento que tenga asignado el interno FIES; constantes recuentos y cacheos cada vez que se entra y se sale de la celda, esto es, al menos cuatro veces al día; registros de celda y requisas; cambios periódicos de celda; las llamadas rondas nocturnas, con una frecuencia no superior a dos horas o a una si el sujeto está en régimen cerrado; no saber cuándo se producirán las salidas en traslados, ni siquiera cuando se deben a razones médicas o por tener una cita con la justicia. Estas medidas constituyen la base para realizar el reproche de vulneración de derechos fundamentales, y, además, no sobra apuntar que si se aspira a que los internos entiendan la importancia de respetar los derechos fundamentales de los demás y se comprometan a respetarlos, se deben respetar también los suyos.

Y a ello todavía quisiera añadir que las prácticas de vigilancia y control a las que se recurre es posible que también inevitablemente, o al menos muy probablemente, afecten no sólo al régimen de vida sino también a la clasificación y a los permisos de salida. Desde la aprobación de la Instrucción 8/2014, de 11 de julio, la Dirección General de Instituciones Penitenciarias no esconde que quien esté incluido en un fichero FIES es porque tiene la consideración de peligroso o de potencialmente peligroso $\mathrm{y}$, por tanto, no va a tener nada fácil beneficiarse de instituciones resocializadoras como lo son los permisos ordinarios de salida, el tercer grado y, con él, el régimen abierto y la libertad condicional, pues de lo que se trata es de garantizar su inocuización. De hecho, en la propia Instrucción 2/2016, 
de 25 de octubre, antes de hablarse del Programa Marco de Intervención y Tratamiento para Internos Islamistas Radicalizados, se advierte que frente a los delincuentes terroristas se adoptan una serie de medidas incapacitadoras, haciéndose mención a la imposición de mayores exigencias para el acceso a los beneficios penitenciarios, a las especiales prevenciones respecto a la clasificación penitenciaria y a la política de dispersión. Sucede, sin embargo, que estas medidas de excepción no únicamente afectan a los condenados por terrorismo, también a los sospechosos de radicalización o de ser radicalizados.

Se parte, a mi modo de ver, de una defensa social mal entendida, y también de un concepto inadecuado, o incompleto, si se prefiere, del tratamiento penitenciario. Todo cuanto ayude a la realización efectiva de la meta resocializadora tiene que considerarse tratamiento. Éste debe dejar de concebirse como una tarea exclusiva de los especialistas y tiene que pasar a verse como una realidad del trabajo diario, como una tarea de todos. De hecho, que debe ser así se desprende de lo indicado en relación con el mismo en el Reglamento Penitenciario, tal y como hemos visto. El tratamiento es la herramienta a través de la cual se aspira a conseguir la resocialización, pero tiene que entenderse como un todo, con lo cual, si por una parte se allana el camino, pero por la otra se ponen obstáculos, es difícil su consecución, y aspirar a la defensa social sin tomarse en serio la resocialización es una paradoja.

\section{Bibliografía}

ACALE SÁNCHEZ, M., “Terrorismo y tratamiento punitivista: más allá de la prisión”, en PÉREz CEPEDA, I. (Dir.), El terrorismo en la actualidad: un nuevo enfoque politico criminal, Tirant lo Blanch, Valencia, 2018.

Altier, M. B., Thoroughgood, C.N. y Horgan, J.G., "Turning away from terrorism: Lessons from psychology, sociology and criminology", Journal of Peace Research, vol. 51, núm. 5, 2014.

Álvarez García, F.J., Consideraciones sobre los fines de la pena en el ordenamiento constitucional español, Comares, Granada, 2001.

Antón OnecA, J., La utopía penal de Dorado Montero, Universidad de Salamanca, Salamanca 1951.

Arenal, C., El visitador del preso, prólogo de Manuela Carmena, edición realizada por la Asociación de Colaboradores con las Presas, Madrid, 1991.

ARENAL, C., Estudios penitenciarios, segunda edición, Imprenta de T. Fortanet, Madrid, 1877.

Bacigalupo, E., "Significación y perspectivas de la oposición 'Derecho Penal-Política Criminal”, Révue Internationalde de Droit Pénal, 1977. 
BARRELlE, K., "Prointegration: disengagement from and life after extremism”, Behavioral Sciences of Terrorism and Political Aggression, vol. 7, núm. 2, 2015.

Bartlett, J. y Miller, C., “The Edge of Violence: Towards Telling the Difference Between Violent and Non-Violent Radicalization", Terrorims and Political Violence, núm. 24, 2012.

BERGALLI, R., ¿Readaptación social por medio de la ejecución penal?, Instituto de Criminología de Universidad Complutense, Madrid, 1976.

BlaU, G., "Aufgaben und Grenzen der Kriminalpädagogik", en Vv. Aa., Erziehung zur Freiheit durch Freiheitsentzung, Internationale Problem des Strafvollzugs an jungen Menschen, Hermann Luchterhand, Berlín, 1969.

BLAU, G., "Kustodial und antikustodiale Tendenzen in der amerikanischen Kriminalpolitik", Goltdammers Archiv, 1976.

Bueno Arus, F., “A propósito de la resocialización del delincuente”, Cuadernos de Política Criminal, núm. 25, 1985.

Cano Paños, M. A., Régimen Penitenciario de los terroristas en España. La prisión como arma para combatir ETA, Dykinson, Madrid, 2018.

Carou-García, S., "Yihadismo y Derecho Penitenciario. La prevención del extremismo violento en prisión desde una perspectiva tratamental", Anuario de Derecho Penal y Ciencias Penales, vol. LXXII, 2019.

Cerezo Mir, J., Curso de Derecho Penal español Parte General, sexta edición, Tecnos, Madrid, 2004.

Clemmer, D., The Prison Community, Holt Rinehart and Winston, New York, 1958.

Cobo del Rosal, M. y Vives Antón, T.S., Derecho Penal. Parte General, quinta edición, Tirant lo Blanch, Valencia, 1999.

De la Cuesta Arzamendi, J.L., "La resocialización: objetivo de la intervención penitenciaria”, Papers d'Estudis i Formació, núm.12, diciembre de 1993.

Dorado Montero, P., El Derecho protector de los criminales (Nueva edición muy aumentada y rehecha de los Estudios de Derecho Penal preventivo), Victoriano Suárez, Madrid, 1915.

Eser, A., "Resozialisierung in der Krise? Gedanken zum Sozialisationsziel des Strafvollzugs", Einheit und Vielfalt des Strafrechts: Festschrift für Karl Peters, núm. 70, 1974.

FERnÁNDEZ ABAD, C., "La doble problemática del Terrorismo Yihadista en prisión. Una aproximación crítica a la respuesta del sistema penitenciario español”, InDret, núm. 4, 2020.

FERnÁNDEz ABAD, C., “Las prisiones como 'espacios de oportunidad' en la lucha contra el terrorismo yihadista: ¿Idoneidad de la respuesta española?”, Revista General de Derecho Penal, núm. 34, 2020. 
García-Pablos de Molina, A., "Sobre la función resocializadora o rehabilitadora de la pena”, Cuadernos de Política Criminal, segunda época, núm. 100, 2010.

García-Pablos de Molina, A., Estudios penales, Bosch, Barcelona, 1984.

García-Pablos de Molina, A., Introducción al Derecho Penal, quinta edición, Editorial Universitaria Ramón Areces, Madrid, 2012.

Garrido Genovés, V. y PiÑAnA, A.M., “El modelo cognitivo aplicado a delincuentes institucionalizados: el pensamiento prosocial”, Revista Complutense de Educación, vol. 7, núm. 2, 1996.

GARRIDO GENOVÉs, V., "El modelo cognitivo en la prevención y tratamiento de la delincuencia. Aplicaciones en delincuentes españoles", en Delincuencia, vol. 1, núm. 2, 1989.

Garrido Genovés, V., Técnicas de tratamiento para delincuentes, Cera S.A., Madrid, 1993.

Goffman, E., Asylums: Essays on the Social Situation of Mental Patients and Other Inmates, Doubleday, New York, 1961.

GonzÁlez Collantes, T., "La convivencia de dos conceptos del tratamiento resocializador en el ordenamiento penitenciario español”, Revista General de Derecho Penal, núm. 22, 2014.

GonzÁlez Collantes, T., "Prisión y terrorismo yihadista: los FIES como medida penitenciaria de prevención de atentados, de adiestramiento y reclutamiento con fines terroristas", en Alonso Rimo, A., Cuerda ARnaU, M.L. y Fernández Hernández, A. (Dirs.), Terrorismo, sistema penal y derechos fundamentales, Tirant lo Blanch, Valencia, 2018.

GonzÁlez Collantes, T., El concepto de resocialización (Desde un punto de vista histórico, sociológico, jurídico y normativo), Tirant lo Blanch, Valencia, 2021.

GonzÁLEz Rus, J.J., “Teoría de la pena y Constitución”, en Estudios Penales y Criminológicos, VII, 1982-1983.

Horgan, J. y Altier, B., “The Future of Terrorism De-Radicalization Programs", Georgetown Journal of International Affairs, vol. 13, núm. 2, 2012.

HoRgan, J., "Deradicalization or Disengagment? A process in Need of Clarity and a Counterterrorism Initiative in Need of Evaluation", Perspectives on Terrorism, vol. 2, núm. 4, 2008.

Koehler, D., Understanding Deradicalization. Methods, tools and programs for countering violent extremism, Routledge, New York, 2017.

LAMARCa PÉREz C., "Régimen penitenciario y derechos fundamentales", en Estudios Penales y Criminológicos, núm. 16, 1992-1993.

LuZón PeÑA, D., Medición de la pena y sustitutivos penales, Instituto de Criminología, Universidad Complutense, Madrid, 1979. 
Manzanares Samaniego, J.L., "Concepto, voluntariedad y principios inspiradores del tratamiento", en CoBo DEL Rosal, M., Comentarios a la Legislación Penal. La Ley Orgánica General Penitenciaria, Edersa, Madrid, 1986.

Mapelli Caffarena, B., Principios fundamentales del sistema penitenciario español, Bosch, Barcelona, 1983.

Mena Álvarez, J.M., “Reinserción, ¿para qué?”, Revista Jueces para la Democracia, núm. 32, julio 1998.

Müller-Dietz, H., "Strafvollzugsrecht und Strafvollzugsreform”, en MschrKrim, 1972.

Müller-Dietz, H., Wege zur Strafvollzugsreform, Duncker\&Humblot, Berlín, 1972.

Muñoz Conde, F., "La resocialización del delincuente, análisis y crítica de un mito", en Cuadernos de Política Criminal, núm.7, 1979.

Muñoz Conde, F., "Resocialización y tratamiento del delincuente en los establecimientos penitenciarios españoles", en La Reforma Penal, Ed. Instituto Alemán, Madrid, 1982.

Nass, G., Der Mensch und die Kriminalität, vol. III, Kriminalpädagogik, Behandlung und Resozialisierung des Rechtsverbrechers, Carl Heymanns, Köln, 1968.

Neuman, P., "Radikalisierung, Deradikasierung und Extremismus", Aus Politik und Zeitgeschicte, núm. 29-32, 2013.

Neuman, P., Prison and Terrorism. Radicalisation and Deradicalisation in 15 countries, The International Centre for the Study of Radicalisation and Political Violence, Maryland, 2010. Trabajo disponible online en: https://www.clingendael.org/ sites/default/files/pdfs/Prisons-andterrorism-15-countries.pdf.

Neumann, P.R., Victims, Perpetrators, Assets: The Narrative of Islamic State Defectors, The International Centre for the Study of Radicalisation and Political Violence, 2015. Trabajo disponible online en: https:// icsr.info/wp-content/uploads/ 2015/10/ICSR-Report-Victims-Perpetrators-Assets-The-Narratives-of-Islamic-State-De fectors.pdf.

Octavio de Toledo Y Ubieto, E., Sobre el concepto del Derecho Penal, Universidad de Madrid, Facultad de Derecho, Sección Publicaciones, Madrid, 1981.

Peña Roldán, L., "Resocialización. Un problema de todos”, en Anales de Derecho, Universidad de Murcia, núm., 14, 1996.

Peters, K., "Die ethischen Voraussetzungen des Resozialisierungs und Erziehungsvollzuges”, Festschrift für E. Heinitz, núm. 70, 1972. 
Petrus Rotger, A., "Hacia una pedagogía comunitaria de la pedagogía penitenciaria”, en Pedagogía social: revista interuniversitaria, núm. 7, 1989.

Plamenatz, J.P., Libertad, consentimiento y obligación política, Fondo de Cultura Económica, México, 1970.

Rabasa, A., Pettyjohn, S.L., Ghez, J. y Boucek, C., Deradicalizing Islamist Extremist, National Security Research Division, Santa Monica, p. XIII. Trabajo disponible online en: https:/www.rand.org/content/ dam/rand/pubs/monographs /2010/RAND_MG1053.pdf.

REDONDO Illescas, S. y GARRIDO GenOvÉs. V., "El tratamiento y la intervención en las prisiones. El ideal de la rehabilitación y la intervención en las prisiones”, en Delincuencia, vol. 3, núm. 3, 1991.

REINARES, F., "Exit from Terrorism: Qualitative Empirical Study on Disengagement and Deradicalization Among Members of ETA", Terrorism and Political Violence, vol. 23, 2011.

Revelles CARrasco, M., "Intervención contra el yihadismo en prisión”, InDret, núm. 4, 2020.

RoEDER, C.D., Estudios sobre Derecho Penal y sistemas penitenciarios: fundamento jurídico de la pena correccional, traducción a cargo de Vicente Romero Girón, Imprenta de T. Fortanet, Madrid, 1875.

Ross, R., Fabiano, E., Garrido, V. y Gómez, A., El Pensamiento Prosocial: la práctica. Un modelo cognitivo para la prevención y el tratamiento de la delincuencia, MEPSA, Madrid, 1994.

Ross, R., FABIANO, E. y Ross, R. D., Reasoning and rehabilitation: cL laidback for teaching cognitive skills, University of Otawa, Otawa, 1989.

Ross, R., FABIANo, E. y GARRIDo Genovés, V., "El pensamiento prosocial. El modelo cognitivo para la prevención y tratamiento de la delincuencia”, en Delincuencia, núm. 1, monográfico, 1990.

Roxin, C., "Sentido y límites de la pena estatal", en Problemas básicos del Derecho Penal, traducción y notas de Diego-Manuel Luzón Peña, Editorial Reus, Madrid, 1976.

SpecKHARD, A. y YAYA, A.S., "Eyewitness Accounts from Recent Defectors from Islamic State: Why They Joined, What They Saw, Why They Quit", Perspectives on Terrorism, vol. 9, núm. 6, 2015.

Tamarit Sumalla, J.M., García Albero, R. Rodríguez Puerta, M.J. y Sapena Grau, F., Curso de Derecho Penitenciario, segunda edición, Tirant lo Blanch, Valencia, 2005.

Vidino, L., “Deradikalisierung durch gezielte Interventionen”, Aus Politik und Zeitgeschichte, núm. 29-31, 2013.

Vives Antón, T.S., "Introducción, Estado de Derecho y Derecho Penal", en Coвo Del Rosal, M. (Dir.), Comentarios a la Legislación Penal, Derecho Penal y Constitución, Edersa, Madrid, 1982. 